\title{
Identification of quantitative trait loci governing early germination and seedling vigor traits related to weed competitive ability in rice
}

\author{
Niña Gracel B. Dimaano (iD) J Jauhar Ali (D) Anumalla Mahender (D) \\ Pompe C. Sta. Cruz 1 - Aurora M. Baltazar • Maria Genaleen Q. Diaz $(\mathbb{D} \cdot$ \\ Yun Long Pang • Bart L. Acero Jr. • Zhikang Li
}

Received: 14 March 2020/Accepted: 4 September 2020/Published online: 19 September 2020

(C) The Author(s) 2020

\begin{abstract}
Weed competitive ability (WCA) is vital for the improvement of grain yield under direct-seeded and aerobic rice ecosystems where weeds are a major limiting factor. Early seed germination (ESG) and early seedling vigor (ESV) are the crucial traits for WCA. This study attempted to map the quantitative trait loci (QTLs) and hotspot regions governing ESG and ESV traits. A total of $167 \mathrm{BC}_{1} \mathrm{~F}_{5}$ selective introgression lines developed from an early backcross population involving Weed Tolerant Rice 1 (WTR-1)
\end{abstract}

Niña Gracel B. Dimaano, Jauhar Ali, and Anumalla Mahender have contributed equally.

Electronic supplementary material The online version of this article (https://doi.org/10.1007/s10681-020-02694-8) contains supplementary material, which is available to authorized users.

N. G. B. Dimaano · P. C. Sta. Cruz •

A. M. Baltazar · M. G. Q. Diaz

University of the Philippines Los Baños, 4031 Los Baños,

Laguna, Philippines

J. Ali $(\bowtie)$ · A. Mahender · B. L. Acero Jr.

Rice Breeding Platform, International Rice Research Institute (IRRI), 4031 Los Baños, Laguna, Philippines e-mail: J.Ali@irri.org

Y. L. Pang

State Key Laboratory of Crop Biology, College of Agronomy, Shandong Agricultural University,

Taian 271018, People's Republic of China as the recipient parent and $\mathrm{Y}-134$ as the donor parent were phenotyped for ESG and ESV traits. Analysis of variance revealed significant differences in ESGrelated traits except for root length and in ESV-related traits except for plant height at 7 days after sowing. A total of 677-high quality single nucleotide polymorphism (SNP) markers were used to analyze the marker-trait association from a $6 \mathrm{~K} \mathrm{SNP}$ genotyping array. Forty-three QTLs were identified on all chromosomes, except on chromosomes 4 and 8. Thirty QTLs were contributed by a desirable allele from Y-134, whereas 13 QTLs were from WTR-1. Twentyeight of the identified genetic loci associated with ESG and ESV traits were novel. Two QTL hotspot regions were mapped on chromosomes 11 and 12. The genomic regions of QTL hotspots were fine-tuned and a total of 13 putative candidate genes were

\section{Z. Li}

National Key Facility for Crop Gene Resources and Genetic Improvement, Institute of Crop Science, Chinese Academy of Agricultural Sciences (CAAS), Beijing 100081, People's Republic of China 
discovered on chromosomes 11 and 12 collectively. The mapped QTLs will be useful in advancing the marker aided-selection schemes and breeding programs for the development of rice cultivars with WCA traits.

Keywords Early seed germination - Early seedling vigor - Selective introgression lines - Quantitative trait loci $\cdot$ Single nucleotide polymorphism $\cdot$ Weed competitive ability

\section{Introduction}

Rice is a major food crop for half of the world's population. By 2050, $42 \%$ more rice yield will be needed to meet the rapidly growing global demand (Ray et al. 2013). Unfortunately, the increase of global rice production is constrained by various biotic and abiotic stresses in diverse rice ecosystems (Pandey et al. 2017). The future threat to natural resources, rising labor shortages, declining arable lands, increasing prices of fertilizer and pesticide inputs, energy scarcity, and changing climatic conditions are the major factors contributing to the decrease in rice production (Singh et al. 2013). To overcome these constraints, shifting from the conventional puddled transplanted rice system to direct-seeded rice (DSR) is the most promising strategy (Chauhan and Abugho 2013; Mahender et al. 2015). DSR has several advantages such as reducing water usage by $35 \%$ to $75 \%$, decreasing labor demand, shortening the crop duration, mitigating methane gas emissions, and lowering the cost of cultivation (Mahender et al. 2015). However, the vigorous growth of weeds is one of the major biological constraints to attain optimal grain yield in the DSR system (Chauhan et al. 2015).

Many options exist to control weeds in the DSR system, such as tillage operations and herbicide applications. However, tillage approaches are laborious, while herbicide use requires multiple applications during the cropping season, thus increasing the financial burden on farmers (Rahman et al. 2012). Appleby et al. (2002) have estimated that more than USD 100 billion are lost annually due to weed-control practices globally. Therefore, urgent attention is required to develop alternative sustainable weed management technologies for the DSR system.
Breeding for cultivars with weed competitive ability (WCA) is a promising strategy to reduce tillage operations and herbicide inputs in the DSR system. Rice cultivars with WCA can suppress the growth of weeds without a yield penalty under weedy conditions (Dimaano et al. 2017). WCA is a complex and polygenic trait, which is governed by several agromorphological features related to early seed germination (ESG) and early seedling vigor (ESV). WCA is significantly involved in DSR and aerobic rice cultivation (Okami et al. 2011; Mahender et al. 2015).

In the DSR system, there is no standing water and seedling size advantage to suppress weed growth and emergence. The ESG and ESV traits are crucial in the early crop establishment and successful competition of rice cultivars against weeds (Haque et al. 2007; Mahajan et al. 2014; Dimaano et al. 2017). In order to identify the weed competitive rice cultivars for the DSR system, the rice plant must have early germination capacity and faster seedling vigor. ESV is a highly repeatable trait that can be used to discriminate rice cultivars that have a strong or weak ability for weed competition (Caton et al. 2003). Several researchers reported that germination rate and seedling vigor had significant positive correlations with field emergence, seedling establishment, germination rate, plant height, and seedling dry weight (Yang et al. 2010; Mahajan et al. 2014; Dimaano et al. 2017; Zhang et al. 2017). The rate of seedling emergence, ability to germinate, and early seedling growth of shoot and root traits are the major factors for crop establishment, which provides superior root growth that can help in the absorption of more nutrients (Matsushima and Sakagami 2013; Singh et al. 2015; Khan et al. 2016). The uniformity of seedling growth and germination percentages were significantly associated with strong, vigorous crop growth and better seedling establishment, which can influence the improvement of yield (Cui et al. 2002a; Diwan et al. 2013; Dang et al. 2014). In addition, several traits that are significantly linked to WCA include plant height (Mahajan et al. 2014), tiller number (Kaur and Singh 2014), leaf area index (Rao et al. 2007), mesocotyl elongation (Lee et al. 2012), early crop biomass (Ni et al. 2000), shoot and root dry weight (Zhao et al. 2006a, b; Lu et al. 2007; Yang et al. 2010; Okami et al. 2011), and canopy ground cover (Anwar et al. 2012).

The identification of quantitative trait loci (QTLs) for ESG and ESV traits which are fundamental for 
WCA will provide useful information in the markeraided selection for weed competitive genotypes. Therefore, this study was conducted to investigate the QTLs and hotspot regions governing the ESG and ESV traits using a $\mathrm{BC}_{1} \mathrm{~F}_{5}$ early backcross selective introgression lines (SILs) derived from a cross between Weed Tolerant Rice-1 (recipient parent) and Y-134 (donor parent). In this study, we assessed the phenotypic variance of the key traits related to ESG and ESV and mapped the QTLs governing these traits using a high-quality single nucleotide polymorphism (SNP) array. Our results revealed novel QTLs for ESG and ESV traits, thus advance the understanding of the association of rice genomic regions and key WCA traits.

\section{Materials and methods}

Plant materials

A total of $167 \mathrm{BC}_{1} \mathrm{~F}_{5}$ generation of early backcross SILs of a Green Super Rice (GSR) IR2-6 population were derived from a cross between Weed Tolerant Rice 1 (WTR-1) as a recipient parent and Y-134 as a donor parent developed at the International Rice Research Institute (IRRI). WTR-1 is the GSR recipient parent from South China, and is a widely adaptable rice variety with WCA traits; while Y-134 is a highyielding variety and is a potential donor for agronomic traits which were used in the GSR-breeding program (Dimaano et al. 2017; Pang et al. 2017; Ali et al. 2018). Junglerice [Echinochloa colona (L.) Link], one of the most dominant grass weed species in rice fields, was used in the pot experiment to simulate weed competition.

Phenotyping of early seed germination (ESG) traits

Seed dormancy of SILs was broken by incubating the seeds at $50{ }^{\circ} \mathrm{C}$ for 4 days (Jennings and de Jesus 1964). Two replications of 25 seeds from each of the 167 SILs were placed randomly in a 9-cm-diameter Petri dish lined with two layers of wet filter paper and kept in a germination chamber set at $30{ }^{\circ} \mathrm{C} 12 \mathrm{~h}$ photoperiod for 14 days. Seeds showing a $2 \mathrm{~mm}$ radicle length were considered germinated. Seed germination was counted at two different intervals: $48 \mathrm{~h}$ after seed placement as first germination count (1st GC) and 7 days after seed placement as second germination count ( 2 nd GC). Germination percentage (GP-1) was determined as the ratio of $1 \mathrm{st}$ GC to 2 nd GC. At 14 days after seed placement, data were collected for shoot length (SL), root length (RL-1), total fresh weight of germinated seeds (TFGS), and average fresh weight (AFW) of germinated seeds. The AFW was computed by dividing TFGS to the total number of seeds that germinated. SL was measured from the collar region to the tip of the topmost leaf. RL-1 was measured from the collar region down to the tip of the longest root. The total dry weight of germinated seeds (TDGS) was measured after drying at $70{ }^{\circ} \mathrm{C}$ for 5 days. The average dry weight (ADW) was computed by dividing TDGS by the total number of seeds that germinated. Vigor index (VI-1) was calculated by multiplying GP-1 by TDGS (Table 1).

Phenotyping of early seedling vigor (ESV) traits

Two replications of 5 seeds of 167 SILs along with parents WTR-1 and Y-134 were sown in plastic pots filled with soil and grown until 28 days after sowing (DAS) for investigation of seedling vigor traits. The soil type used was Maahas clay loam (iso-hyperthermic mixed Typic-Tropudalf). A compound N-P-K fertilizer $(14: 14: 14)$ was added to each pot based on field recommendations. One hundred seeds of jungle rice [Echinochloa colona (L.) Link] were randomly sown in each pot simultaneously with rice seeds to simulate weed competition. The pots were watered once daily, and the moisture was kept at direct-seeded non-flooded condition. At seven DAS, the germination count (GC) and germination percentage (GP-2) was measured for each SIL. GP-2 was computed by dividing GC by the total number of initial seeds. Seedling plant height $(\mathrm{PH})$ and the number of leaves (NL) were measured at 7, 14, 21, and 28 DAS. The number of tillers (NT) and leaf chlorophyll content (LCC) was recorded at 28 DAS. After each observation at 28 DAS, the seedlings were uprooted carefully, shoots and roots were separated, and values for leaf fresh weight (LFW), root length (RL-2), root fresh weight (RFW), and total fresh weight (TFW) were 
Table 1 Rice agro-morphological characteristics investigated for early seed germination (ESG) and early seedling vigor (ESV) traits

\begin{tabular}{|c|c|c|c|}
\hline \multicolumn{2}{|c|}{ No. } & Trait observations & Description of trait \\
\hline \multicolumn{4}{|c|}{ Early seed germination (ESG) traits } \\
\hline 1 & 1st GC & 1st germination count & Number of germinated seeds after $48 \mathrm{~h}$ \\
\hline 2 & 2nd GC & 2nd germination count & Number of germinated seeds after 7 days \\
\hline 3 & GP-1 & Germination percentage & $\begin{array}{l}\text { The ratio of the } 1 \text { st germination count to the } \\
\text { 2nd germination count }\end{array}$ \\
\hline 4 & SL & Shoot length $(\mathrm{cm})$ & $\begin{array}{l}\text { Measured from the collar region to the tip } \\
\text { of topmost leaf }\end{array}$ \\
\hline 5 & RL-1 & Root length (cm) & $\begin{array}{l}\text { Measured from collar region down to the tip } \\
\text { of the longest root }\end{array}$ \\
\hline 6 & TFGS & Total fresh weight of germinated seeds & Total fresh weight of all seeds that germinated \\
\hline 7 & TDGS & The total dry weight of germinated seeds & $\begin{array}{l}\text { The total dry weight of all seeds that germinated } \\
\text { after drying at } 70{ }^{\circ} \mathrm{C} \text { for } 5 \text { days }\end{array}$ \\
\hline 8 & AFW & Average fresh weight & TGFS/number of seeds that germinated \\
\hline 9 & ADW & Average dry weight & TDGS/number of seeds that germinated \\
\hline 10 & VI-1 & Vigor index & $\begin{array}{l}\text { Germination percentage multiplied by the total } \\
\text { dry weight of germinated seeds }\end{array}$ \\
\hline \multicolumn{4}{|c|}{ Early seedling vigor (ESV) traits } \\
\hline 1 & GC & Germination count & Number of seeds that germinated \\
\hline 2 & GP-2 & Germination percentage & The ratio of the germinated seeds to the total number of seeds \\
\hline 3 & PH at 7 DAS & Seedling plant height $(\mathrm{cm})$ at 7 DAS & Plant height at 7 days after sowing \\
\hline 4 & PH at 14 DAS & Seedling plant height $(\mathrm{cm})$ at 14 DAS & Plant height at 14 days after sowing \\
\hline 5 & $\mathrm{PH}$ at $21 \mathrm{DAS}$ & Seedling plant height $(\mathrm{cm})$ at 21 DAS & Plant height at 21 days after sowing \\
\hline 6 & PH at 28 DAS & Seedling plant height $(\mathrm{cm})$ at 28 DAS & Plant height at 28 days after sowing \\
\hline 7 & NL at 7 DAS & Number of leaves at 7 DAS & Number of leaves at 7 days after sowing \\
\hline 8 & NL at 14 DAS & Number of leaves at 14 DAS & Number of leaves at 14 days after sowing \\
\hline 9 & NL at 21 DAS & Number of leaves at $21 \mathrm{DAS}$ & Number of leaves at 21 days after sowing \\
\hline 10 & NL at 28 DAS & Number of leaves at 28 DAS & Number of leaves at 28 days after sowing \\
\hline 11 & NT & Number of tillers & Number of tillers per plant \\
\hline 12 & LCC & Leaf chlorophyll content & Reading-based on Soil-Plant Analyses Development meter \\
\hline 13 & VI-2 & Vigor index & Germination percentage multiplied by total dry weight \\
\hline 14 & LFW & Leaf fresh weight $(\mathrm{g})$ & Fresh weight of leaves \\
\hline 15 & LDW & Leaf dry weight $(\mathrm{g})$ & The dry weight of leaves after drying at $70{ }^{\circ} \mathrm{C}$ for 5 days \\
\hline 16 & RFW & Root fresh weight (g) & Fresh weight of roots \\
\hline 17 & RDW & Root dry weight (g) & The dry weight of roots after drying at $70{ }^{\circ} \mathrm{C}$ for 5 days \\
\hline 18 & TFW & Total fresh weight $(\mathrm{g})$ & Measured by computing leaf fresh weight + root fresh weight \\
\hline 19 & TDW & Total dry weight $(\mathrm{g})$ & Measured by computing leaf dry weight + root dry weight \\
\hline 20 & RL-2 & Root length (cm) & Measured from collar region down to the tip of the longest root \\
\hline
\end{tabular}

collected. The plant samples were oven-dried at $70{ }^{\circ} \mathrm{C}$ for 5 days then measured for leaf dry weight (LDW), root dry weight (RDW), and total dry weight (TDW). Vigor index (VI-2) was computed by multiplying GP2 by TDW. The weed density (WD), weed fresh weight (WFW), and weed dry weight (WDW) were collected at 28 DAS to correlate with rice seedling vigor performance and to assess WCA. Junglerice shoots were cut at the soil surface, weighed for WFW, oven-dried at $70{ }^{\circ} \mathrm{C}$ for 5 days, and weighed for WDW (Table 1). 
Statistical analysis

All phenotypic data of ESG- and ESV-related traits were analyzed using Plant Breeding Tools version 1.4 (IRRI 2017) for descriptive statistics including mean, minimum and maximum values, standard deviation, coefficient of variation (\%), and correlation analysis and analysis of variance (ANOVA) at $1 \%$ level of significance. The heat maps of Pearson's correlation coefficient were generated using the corrplot package and the broad-sense heritability was calculated based on the replicated data and random-effects ANOVA using the lmer package in R software (R Development Core Team 2012).

DNA extraction and genotyping

Leaf samples were collected from each of the SILs and parents at 21 DAS. The genomic DNA was extracted and purified following a modified CTAB method (Murray and Thompson 1980) and quantified by using NanoDrop 8000 spectrophotometer (Thermo Scientific, USA). The concentration of the extracted DNA sample was adjusted to $50 \mathrm{ng} \mu \mathrm{l}^{-1}$ and used in the $6 \mathrm{~K}$ SNP array. DNA quantification, incubation, hybridization of bead chip, staining, and image scanning were performed according to the manufacturer's instructions for the Illumina Infinium assay at the Genotyping Services Laboratory of IRRI. The resulting intensity data were processed for SNP calling by using genotyping module V2011.1 of Genome Studio software (Illumina Inc., San Diego, CA, USA). The genotypic data from the $6 \mathrm{~K} \mathrm{SNP}$ array were filtered according to the methods described by Najeeb et al. (2020), and the obtained polymorphic SNPs between the parents were used to map the QTLs for ESG and ESV traits.

\section{QTL mapping}

For the QTL analysis, the mean phenotypic trait values (across replications) of 167 SILs and the corresponding SNP marker data were used. A total of 677 polymorphic SNP markers covering $>90 \%$ of all chromosomes and their physical positions were used to construct the physical map (Table 2). The QTL mapping was performed by single-marker regression analysis using the function of single marker analysis (SMA) in IciMapping software v4.1 (www.isbreeding. net/software/?type=detail\&id=18) (Meng et al. 2015).
The threshold $(-\log p(\mathrm{~F}) \geq 2.9)$ to declare a significant association between marker and trait was set based on a permutation test $(n=1000 ; P=0.01)$ (Churchill and Doerge 1994). For the additive effect, a positive value means that the desirable allele is from the recipient parent (WTR-1), while a negative value means that the desirable allele is from the donor parent (Y-134). The graphical representation of the polymorphic SNPs and the location of the peak marker was visualized using the physical positions of each marker in PhenoGram software (Wolfe et al. 2013).

Identification of putative candidate genes associated with ESG and ESV traits

In order to predict and identify the presence of putative candidate genes within the identified QTLs associated with ESV and ESG traits, in silico analysis was performed using the rice genome browser databases such as MSU Rice Annotation Project (RAP) (https:// rapdb.dna.affrc.go.jp/) and Oryzabase database (https: //shigen.nig.ac.jp/rice/oryzabase/). To view the list of identified QTLs and find the co-localized QTLs with the present QTLs, QTL Annotation Rice Online database tools (Q-TARO) (http://qtaro.abr.affrc.go.jp/) and Gramene database (https://archive.gramene.org/) were used.

\section{Results}

Phenotypic variation of ESG-related traits

ESG traits are the key components to improve WCA in rice. A total of ten ESG traits (1st GC, 2nd GC, GP-1, SL, RL-1, TFGS, TDGS, AFW, ADW, and VI-1) were investigated in 167 SILs and the results showed high phenotypic variation among the SILs. The mean GP-1 of WTR-1 and Y-134 was 68\% and 94\%, respectively, while the overall average for all SILs was $63.90 \%$ (Supplementary Table 1). More than 90\% germination was observed in 11 SILs, including the donor parent Y-134. In the same set of SILs, we found the highest values for VI-1 in the range of 27.60 to 37.35 . Among the ten ESG traits, the highest coefficients of variation $(C V)$ values were identified in $\mathrm{AFW}$ $(48.25 \%)$ and 1 st GC after $48 \mathrm{~h}(44.05 \%)$, whereas the lowest $C V$ was observed in TDGS (17.83\%) and SL (18.58\%). Analysis of variance (ANOVA) of these 
Table 2 Summary of markers used in genotyping $167 \mathrm{BC}_{1} \mathrm{~F}_{5}$ early backcross selective introgression lines (SILs) developed from an early backcross population involving Weed Tolerant Rice 1 as the recipient parent and Y-134 as the donor parent

\begin{tabular}{llllll}
\hline Chromosome & $\begin{array}{l}\text { Number of } \\
\text { markers }\end{array}$ & $\begin{array}{l}\text { Average distance } \\
(\mathrm{Kb})\end{array}$ & $\begin{array}{l}\text { Genome size covered by } \\
\text { SNPs }(\mathrm{Kb})\end{array}$ & $\begin{array}{l}\text { Total rice genome size } \\
(\text { Gramene) }\end{array}$ & $\begin{array}{l}\text { Coverage } \\
\text { percentage }(\%)\end{array}$ \\
\hline 1 & 77 & 549.3 & $42,297.1$ & $43,270.9$ & 97.7 \\
2 & 53 & 651.2 & $34,511.0$ & $35,937.3$ & 96.0 \\
3 & 61 & 573.3 & $34,970.6$ & $36,413.8$ & 96.0 \\
4 & 35 & 939.8 & $32,891.7$ & $35,502.7$ & 92.6 \\
5 & 55 & 513.4 & $28,236.0$ & $29,958.4$ & 94.3 \\
6 & 74 & 392.5 & $29,043.4$ & $31,248.8$ & 92.9 \\
7 & 76 & 378.4 & $28,758.3$ & $29,697.6$ & 96.8 \\
8 & 56 & 492.1 & $27,559.2$ & $28,443.0$ & 96.9 \\
9 & 47 & 466.3 & $21,918.2$ & $23,012.7$ & 95.2 \\
10 & 35 & 505.7 & $17,699.3$ & $23,207.3$ & 76.3 \\
11 & 58 & 488.1 & $28,309.3$ & $29,021.1$ & 97.5 \\
12 & 50 & 506.7 & $25,333.7$ & $27,531.9$ & 92.0 \\
\end{tabular}

Kb-kilobase

traits revealed a significant difference $(P<0.001)$ in ten traits, except RL-1 $(P=0.0834)$ and SL $(P=0.0137)$ (Table 3).

In the pair-wise correlation coefficient of ESG traits, 1st GC positively and significantly correlated with 2nd GC, GP-1, TDGS, TFGS, and VI-1 ( $\mathrm{r}=0.58$, $\mathrm{r}=0.57, \mathrm{r}=0.49, \mathrm{r}=0.30, \mathrm{r}=0.58, P<0.001)$, whereas a significant negative correlation was observed with AFW ( $\mathrm{r}=-0.40, P<0.001)$, ADW $(\mathrm{r}=-0.21, \quad P<0.001), \quad$ and $\mathrm{SL} \quad(\mathrm{r}=-0.13$, $P<0.01$ ) (Supplementary Fig. 1). VI-1 was strongly associated with 1st GC, 2nd GC, GP-1, TFGS, and TDGS. The highest correlation value was recorded between the traits 2nd GC and VI-1 $(\mathrm{r}=0.94$, $P<0.001)$, GP-1 and VI-1 $(\mathrm{r}=0.94, P<0.001)$, and TDGS and VI-1 $(\mathrm{r}=0.86, P<0.001)$, whereas a negative significant correlation was observed between 1st GC with AFW $(\mathrm{r}=-0.40)$ and ADW $(\mathrm{r}=-0.21)$, 2nd GC with AFW $(\mathrm{r}=-0.66)$ and ADW $(r=-0.45)$, GP-1 with AFW $(r=-0.63)$ and ADW $(r=-0.41)$, TFGS with AFW $(r=-0.40)$, AFW and VI-1 $(\mathrm{r}=-0.51)$, and ADW with VI-1 $(\mathrm{r}=-0.26)$ at $P<0.001$.
Phenotypic variation of ESV-related traits

High phenotypic variation was observed in 17 ESVrelated traits. The averages and $C V$ values of the phenotypic traits are presented in Supplementary Table 1. Nine out of 167 SILs showed a VI-2 value of more than 130 and also had maximum GP-2, NL, PH, LCC, RFW, LFW, LDW, and RDW. Five ESV traits (GC, GP-2, LDW, RDW, and TDW) had $C V$ values of $45.42 \%, 45.42 \%, 45.26 \%, 40.52 \%$, and $50.08 \%$, respectively; whereas the lowest $C V$ values $(<30 \%)$ were observed in PH at 28 DAS, NT, LCC, and $\mathrm{NL}$ at $28 \mathrm{DAS}$. The higher $C V$ suggests that the selected SILs exhibited higher genetic variability.

The summary of ANOVA (Table 4) showed significant genotypic effects on all the traits $(P \leq 0.001)$ at $1 \%$ level, except PH at 7 DAS $(P=0.174)$. Highly significant variation was observed for $\mathrm{PH}$ at $28 \mathrm{DAS}$, NL at 7, 14, 21, and 28 DAS, NT, RL-2, RFW, RDW, and TDW $(P<0.001)$. PH at 21 DAS showed significance only at $5 \%$ level, which indicates that very few QTLs can be located for this trait. The correlation analysis showed that all the ESV traits were significantly and positively correlated with one another except for RDW with GC and GP-2 $(P>0.05 ; \mathrm{r}=0.07)$ (Supplementary Fig. 2). Moreover, all the ESV traits were negatively correlated with 
Table 3 Analysis of variance for the testing of significance of genotype effect per trait for early seed germination (ESG) traits

\begin{tabular}{|c|c|c|c|c|c|}
\hline Trait & Abbreviation & Sum of Squares & Mean Square & $F$ value & $\operatorname{Pr}(>F)$ \\
\hline 1st germination count & 1 st GC & 8383.0 & 50.5 & 2.88 & $0.0000 * * *$ \\
\hline 2nd germination count & 2nd GC & 7918.8 & 47.7 & 3.88 & $0.0000 * * *$ \\
\hline Germination percentage $(\%)$ & GP-1 & $128,918.7$ & 776.6 & 3.79 & $0.0000 * * *$ \\
\hline Shoot length (cm) & SL & $33,068.2$ & 199.2 & 1.41 & $0.0137 *$ \\
\hline Root length (cm) & RL-1 & $54,759.7$ & 329.9 & 1.24 & 0.0834 \\
\hline Total fresh weight of germinated seeds $(\mathrm{g})$ & TFGS & 8.2 & 0.0493 & 2.96 & $0.0000 * * *$ \\
\hline Total dry weight of germinated seeds (g) & TDGS & 1.8 & 0.0107 & 4.06 & $0.0000 * * *$ \\
\hline Average fresh weight & AFW & 0.1 & 0.0007 & 1.44 & $0.0099 * *$ \\
\hline Average dry weight & ADW & 0.01 & 0.0001 & 1.83 & $0.0001 * * *$ \\
\hline Vigor index & VI-1 & $23,039.1$ & 138. 8 & 3.59 & $0.0000 * * *$ \\
\hline
\end{tabular}

Significance codes: $* 0.05 \geq P \geq 0.01 ; * * 0.01 \geq P \geq 0.001 ; * * * P \leq 0.001$

Table 4 Analysis of variance for the testing of significance of genotype effect per trait for early seedling vigor (ESV) traits

\begin{tabular}{|c|c|c|c|c|c|}
\hline Trait & Abbreviation & Sum of squares & Mean square & $\mathrm{F}$ value & $\operatorname{Pr}(>F)$ \\
\hline Germination count & GC & 546.9 & 3.3 & 1.44 & $0.0093 * *$ \\
\hline Germination percentage $(\%)$ & GP-2 & $21,8771.3$ & 1317.9 & 1.44 & $0.0093 * *$ \\
\hline Plant height at 7 DAS $(\mathrm{cm})$ & $\mathrm{PH}$ at $7 \mathrm{DAS}$ & 6096.1 & 36.7 & 1.16 & 0.1742 \\
\hline Plant height at 14 DAS $(\mathrm{cm})$ & $\mathrm{PH}$ at $14 \mathrm{DAS}$ & $17,092.2$ & 102.1 & 1.49 & $0.0050 * *$ \\
\hline Plant height at 21 DAS $(\mathrm{cm})$ & $\mathrm{PH}$ at $21 \mathrm{DAS}$ & $39,066.5$ & 235.3 & 1.31 & $0.0409 *$ \\
\hline Plant height at 28 DAS $(\mathrm{cm})$ & $\mathrm{PH}$ at $28 \mathrm{DAS}$ & $38,934.8$ & 234.6 & 2.19 & $0.0000 * * *$ \\
\hline Number of leaves at 7 DAS & NL at 7 DAS & 130.8 & 0.8 & 1.64 & $0.0008 * * *$ \\
\hline Number of leaves at 14 DAS & NL at 14 DAS & 379.6 & 2.3 & 1.62 & $0.0010 * * *$ \\
\hline Number of leaves at 21 DAS & NL at 21 DAS & 2206.2 & 13.3 & 1.71 & $0.0003 * * *$ \\
\hline Number of leaves at 28 DAS & NL at 28 DAS & 4559.5 & 27.5 & 2.10 & $0.0000 * * *$ \\
\hline Number of tillers & NT & 259.3 & 1.6 & 2.64 & $0.0000 * * *$ \\
\hline Leaf chlorophyll content & $\mathrm{LCC}$ & $17,313.0$ & 104.3 & 1.48 & $0.0061 * *$ \\
\hline Root length (cm) & RL-2 & 5372.4 & 32.4 & 1.67 & $0.0005 * * *$ \\
\hline Leaf fresh weight $(\mathrm{g})$ & LFW & 1801.3 & 10.9 & 1.49 & $0.0055^{* *}$ \\
\hline Leaf dry weight (g) & LDW & 21.3 & 0.1 & 1.56 & $0.0023 * *$ \\
\hline Root fresh weight (g) & RFW & 63.4 & 0.4 & 2.24 & $0.0000 * * *$ \\
\hline Root dry weight (g) & RDW & 1.3 & 0.0 & 1.97 & $0.0000 * * *$ \\
\hline Total fresh weight (g) & TFW & 2213.2 & 13.3 & 1.61 & $0.0012 * *$ \\
\hline Total dry weight (g) & TDW & 30.1 & 0.2 & 1.66 & $0.0006^{* * *}$ \\
\hline Vigor index & VI-2 & $375,273.9$ & 2260.7 & 1.56 & $0.0023 * *$ \\
\hline
\end{tabular}

$D A S$ days after sowing

Significance codes:*0.05 $\geq P \geq 0.01 ; * * 0.01 \geq P \geq 0.001 ; * * * P \leq 0.001$

weed parameters WD, WFW and WDW except for RL-2 with WD and WDW $(P>0.05 ; \mathrm{r}=0.11)$, RFW with WD $(P>0.05 ; \mathrm{r}=0.11)$, and RDW with WDW
$(P>0.05 ; \mathrm{r}=0.1)$. Among the ESV traits, only eight traits had a high positive correlation observed between the traits such as TFW and LFW $(r=0.99)$, TDW and 
LDW ( $\mathrm{r}=0.98), \mathrm{TN}$ and $\mathrm{NL}$ at $28 \mathrm{DAS}(\mathrm{r}=0.88), \mathrm{PH}$ at 21 DAS and NL at 14 DAS $(r=0.87), \mathrm{PH}$ at 14 DAS and NL at 14 DAS ( $r=0.86)$, TDW and TN $(\mathrm{r}=0.80)$, VI-2 with GC and GP-2 $(r=0.88), \mathrm{PH}$ at 7 DAS with PH at 14 DAS $(r=80)$, PH at 21 DAS $(r=84), N L$ at 7 DAS $(r=80)$, and NL at 14 DAS $(\mathrm{r}=0.80)$ (Supplementary Fig. 2).

\section{SNP markers for QTL mapping}

A total of 677 polymorphic SNP markers were detected between the parents. These markers were unevenly distributed across the 12 chromosomes, ranging from 35 SNPs on chromosome 4 and 10 to 77 SNPs on chromosome 1, with an average space of $538.1 \mathrm{~kb}$ between the two adjacent markers (Table 2). More than $70 \%$ of SNPs were located within $0.5 \mathrm{Mb}$ of their closest neighbor (Fig. 1). In the distribution of SNPs that were generated through the $6 \mathrm{~K} \mathrm{SNP}$ array, a total of eight gaps (four sites ranged from 3.6 to $5.0 \mathrm{Mb}$ and another four sites ranged in more than $5.0 \mathrm{Mb}$ ) were found across the genome. The results of these gaps indicate the monomorphic patterns of the SNP markers shared between the two parents. The largest gaps were found on chromosome $4(6.62 \mathrm{Mb})$, chromosome $11(5.83 \mathrm{Mb})$, and chromosome 1 $(5.39 \mathrm{Mb})$, respectively. The filtered 677 polymorphic SNPs were used to analyze the association between the ESG and ESV traits and markers.
QTLs associated with ESG traits

A total of 28 QTLs associated with ESG traits were mapped on seven chromosomes (Fig. 2 and Table 5). Of these, 12 QTLs were located on chromosome 12, eight on chromosome 11 , two each on chromosomes 3 , 6 , and 10, and one each on chromosomes 2 and 5, which explained their phenotypic variance (PV) ranging from $7.9 \%$ to $19.9 \%$, respectively. Eleven QTLs had a desirable allele of WTR-1, which explained the PV of five ESG traits (1st GC, 2nd GC, GP-1, TDGS, and VI-1) ranging from 7.9\% (LOD score $=2.91)$ to $19.9 \%($ LOD score $=8.03)$. Moreover, 18 QTLs had a desirable allele contributed by Y-134 and were significantly associated with six ESG traits (1st GC, 2nd GC, GP-1, TDGS, TFGS, and VI1). Three QTLs for 1st GC and TDGS on chromosome 11 ( $q 1 \mathrm{st} G C_{11.1}, q 1 \mathrm{st} G C_{11.2}$, and $\left.q T D G S_{11.1}\right)$ were explained by $\mathrm{PV}$ values of $15.8 \%, 19.9 \%$, and $14.2 \%$, respectively. The high ranges of PV of the QTLs were controlled by a desirable allele from WTR-1 (Fig. 3). Among these QTLs, one major QTL ( $q 1$ st $\left.G C_{11.2}\right)$ which exhibited the highest PV (19.9\%, LOD score = 8.3) was marked by SNP_11_27994133 on chromosome 11.

For TFGS, two major QTLs ( $q T F G S_{12.1}$ and $q T F G S_{12.2}$ ) on chromosome 12 and one minor QTL $\left(q T F G S_{3.1}\right)$ on chromosome 3 were detected with a desirable allele contributed by the donor parent Y-134. Together, the TFGS QTLs explained 11.2\% of PV. Three major QTLs on chromosomes 11 and 12 that

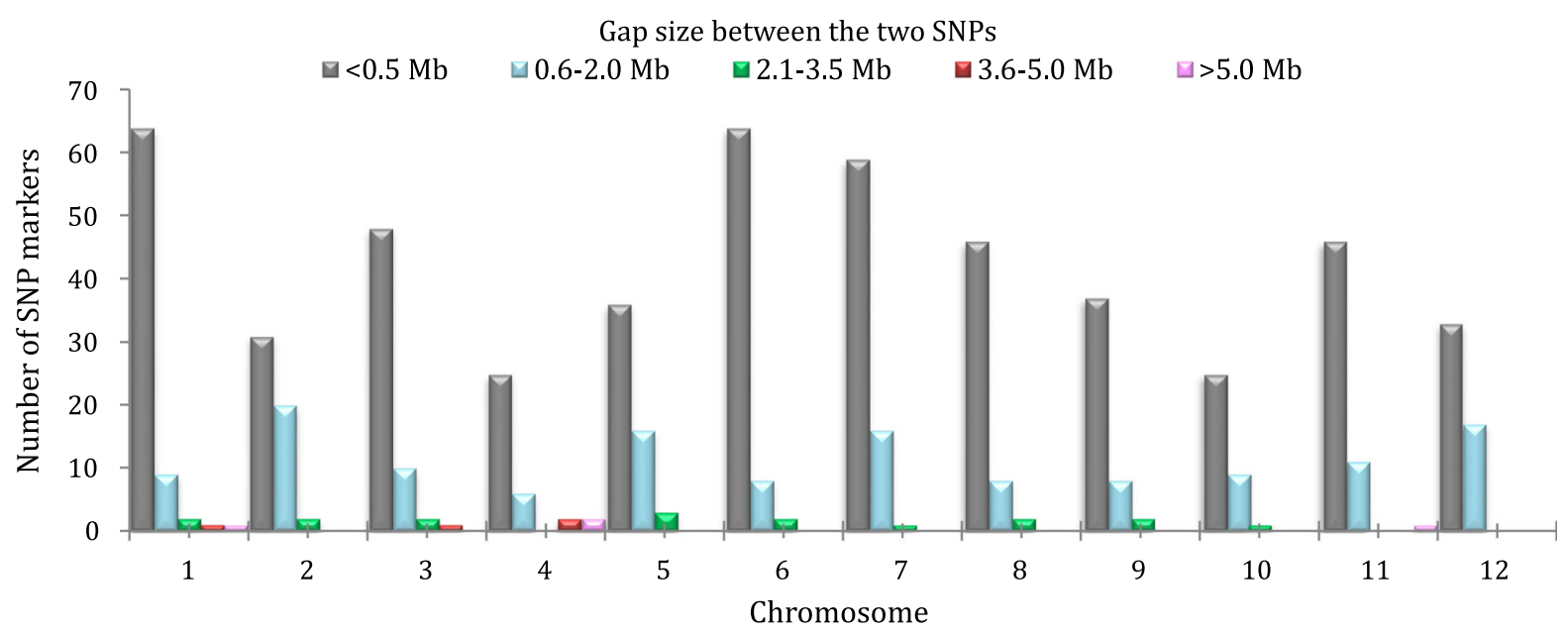

Fig. 1 Distribution of the polymorphic single nucleotide polymorphisms (SNPs) and gaps between the two adjacent markers in all chromosomes 


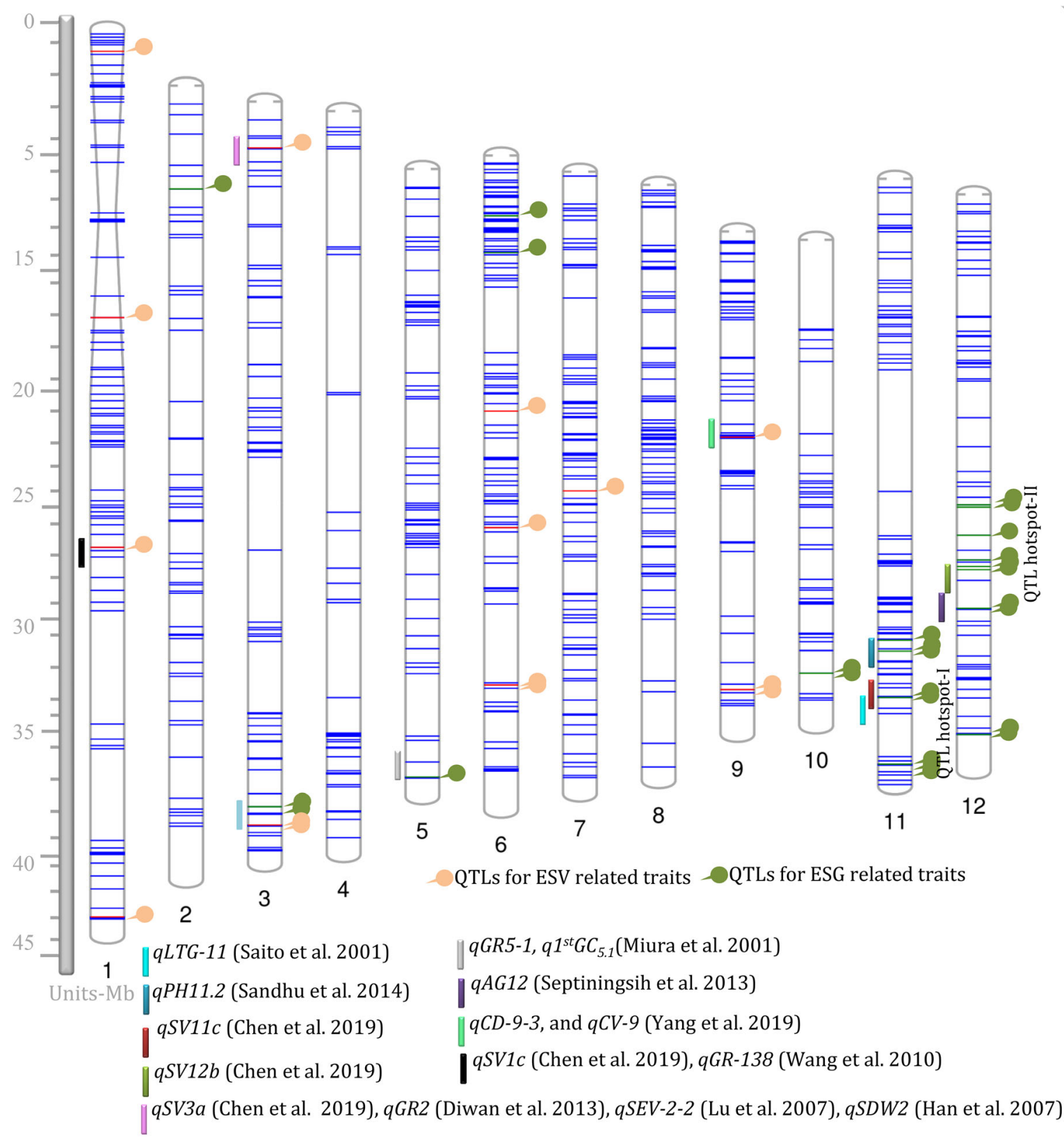

Fig. 2 Phenogram plot showing the forty-three quantitative trait loci (QTLs) for early seed germination (ESG) and early seedling vigor (ESV) related traits in rice. The twelve chromosomes were displayed with blue color lines indicating the distribution of polymorphic single nucleotide polymorphisms (SNPs) according to the physical map. On the left side of the chromosomes were small segments of colored vertical bars representing the previously identified germination and seedling vigor QTLs that co-localized with the QTLs identified in this study. ESG QTLs previously identified were $q$ GR5-1 (Miura et al. 2001), qPH11.2 (Sandhu et al. 2014), qSV11c (Chen et al. 2019), $q L T G-11$ (Saito et al. 2001), qSV12b (Chen et al. 2019), and $q A G 12$ (Septiningsih et al. 2013). ESV QTLs previously identified were $q S V 1 c$ (Chen et al. 2019), $q G R-138$ (Wang et al. 2010), qSV3a (Chen et al. 2019), $q G R 2$ (Diwan et al. 2013), $q S E V-2-2$ (Lu et al. 2007), $q S D W 2$ (Han et al. 2007), and $q C D$ 9-3 and $q C V-9$ (Yang et al. 2019) 
Table 5 QTLs identified for early seed germination (ESG) traits related to weed competitive ability

\begin{tabular}{|c|c|c|c|c|c|c|c|c|}
\hline QTL & Trait & Chr & Position (bp) & Peak marker & LOD & Phenotypic variance $(\%)$ & Additive effect & Parent* \\
\hline$q 1$ st $G C_{2.1}$ & 1st GC & 2 & 4930742 & SNP_2_4930742 & 3.0 & 8.1 & -0.34 & Y-134 \\
\hline$q T D G S_{3.1}$ & TDGS & 3 & 33713486 & SNP_3_33713486 & 3.9 & 10.2 & 0.03 & WTR-1 \\
\hline$q T F G S_{3.1}$ & TFGS & 3 & 33713486 & SNP_3_33713486 & 3.5 & 9.4 & -0.06 & Y-134 \\
\hline$q 1$ st $G C_{5.1}$ & 1st GC & 5 & 29061672 & SNP_5_29061672 & 5.6 & 14.3 & 2.52 & WTR-1 \\
\hline$q 1$ st $G C_{6.1}$ & 1st GC & 6 & 2871279 & SNP_6_2871279 & 3.4 & 9.1 & -1.73 & Y-134 \\
\hline$q 1$ st $G C_{6.2}$ & 1st GC & 6 & 4641044 & SNP_6_4641044 & 3.1 & 8.3 & -1.60 & Y-134 \\
\hline$q 1$ st $G C_{10.1}$ & 1st GC & 10 & 20723502 & SNP_10_20723502 & 3.5 & 9.4 & 1.74 & WTR-1 \\
\hline$q T D G S_{10.1}$ & TDGS & 10 & 20723502 & SNP_10_20723502 & 3.4 & 9.1 & 0.03 & WTR-1 \\
\hline$q 1$ st $G C_{11.1}$ & 1st GC & 11 & 22546707 & SNP_11_22546707 & 6.2 & 15.8 & 2.30 & WTR-1 \\
\hline$q 1$ st $G C_{11.2}$ & 1st GC & 11 & 27994133 & SNP_11_27994133 & 8.0 & 19.9 & 2.65 & WTR-1 \\
\hline$q 2$ nd $G C_{11.1}$ & 2nd GC & 11 & 24779246 & SNP_11_24779246 & 4.3 & 11.3 & 1.93 & WTR-1 \\
\hline$q G P-1_{11.1}$ & GP-1 & 11 & 22044151 & SNP_11_22044151 & 3.0 & 8.2 & 7.24 & WTR-1 \\
\hline$q G P-1_{11.2}$ & GP-1 & 11 & 24779246 & SNP_11_24779246 & 4.3 & 11.3 & 7.73 & WTR-1 \\
\hline$q T D G S_{11.1}$ & TDGS & 11 & 27994133 & SNP_11_27994133 & 5.5 & 14.2 & 0.03 & WTR-1 \\
\hline$q V I-1_{11.1}$ & VI-1 & 11 & 22546707 & SNP_11_22546707 & 2.9 & 7.9 & 2.73 & WTR-1 \\
\hline$q V I-1_{11.2}$ & VI-1 & 11 & 27994133 & SNP_11_27994133 & 5.2 & 13.4 & 3.66 & WTR-1 \\
\hline$q 1 \mathrm{st} G C_{12.1}$ & 1st GC & 12 & 14835375 & SNP_12_14835375 & 3.0 & 8.2 & -1.63 & Y-134 \\
\hline$q 1$ st $G C_{12.2}$ & 1 st GC & 12 & 17788006 & SNP_12_17788006 & 3.1 & 8.3 & -1.62 & Y-134 \\
\hline$q 1$ st $G C_{12.1}$ & 1st GC & 12 & 14936674 & SNP_12_14936674 & 3.0 & 8.3 & -0.37 & Y-134 \\
\hline$q 1$ st $G C_{12.2}$ & 1st GC & 12 & 17443323 & SNP_12_17443323 & 3.0 & 8.3 & -0.37 & Y-134 \\
\hline$q 2$ nd $G C_{12.1}$ & 2nd GC & 12 & 16286946 & SNP_12_16286946 & 3.2 & 8.7 & -1.59 & Y-134 \\
\hline$q 2$ nd $G C_{12.2}$ & 2nd GC & 12 & 17902839 & SNP_12_17902839 & 3.2 & 8.6 & -1.58 & Y-134 \\
\hline$q G P-1_{12.1}$ & GP-1 & 12 & 16286946 & SNP_12_16286946 & 3.2 & 8.7 & -6.37 & Y-134 \\
\hline$q G P-1_{12.2}$ & GP-1 & 12 & 17902839 & SNP_12_17902839 & 3.2 & 8.6 & -6.32 & Y-134 \\
\hline$q T F G S_{12.1}$ & TFGS & 12 & 19786034 & SNP_12_19786034 & 4.2 & 11.1 & -0.03 & Y-134 \\
\hline$q T F G S_{12.2}$ & TFGS & 12 & 25792416 & SNP_12_25792416 & 4.0 & 10.5 & -0.03 & Y-134 \\
\hline$q V I-1_{12.1}$ & VI-1 & 12 & 16287347 & SNP_12_16287347 & 4.1 & 10.8 & -3.05 & $Y-134$ \\
\hline$q V I-1_{12.2}$ & VI-1 & 12 & 25792416 & SNP_12_25792416 & 3.9 & 10.2 & -3.00 & Y-134 \\
\hline
\end{tabular}

*Parent- contributing desirable allele. For the additive effect, a positive value means that the desirable allele is from the recipient parent (WTR-1), while a negative value means that the desirable allele is from the donor parent (Y-134). Abbreviations: Chr, chromosome; LOD, logarithm of the odds; 1st GC, 1st germination count; 2nd GC, 2nd germination count; GP-1, germination percentage; TFGS, total fresh weight of germinated seeds; TDGS, total dry weight of germinated seeds; and VI-1, vigor index

controlled the ESG-related trait VI-1 were $q V I-1_{11.2}$, $q V I-1_{12.1}$, and $q V I-1_{12.2}$, with PV of $13.4 \%, 10.8 \%$, and $10.2 \%$ and a LOD score of 5.21, 4.16, and 3.9, respectively (Table 5 and Fig. 3). The fourth QTL $\left(q V I-1_{11.1}\right)$ explained the PV of $7.9 \%$ and had a LOD score of 2.98. The additive effect of the QTLs on chromosome 11 ( $q V I-1_{11.1}$ and $\left.q V I-1_{11.2}\right)$ was positive, implying that the desirable alleles were contributed by WTR-1, whereas the additive effect of the QTLs on chromosome $12\left(q V I-1_{12.1}\right.$ and $\left.q I V-1_{12.2}\right)$ was negative, and was contributed by Y-134.
QTLs associated with ESV traits

In the present study, 15 QTLs associated with ESVrelated traits (PH at 7, 14, 21, and $28 \mathrm{DAS}, \mathrm{NL}$ at 7 and 21 DAS, RFW, and RDW) were mapped on five different chromosomes (1, 3, 6, 7, and 9). Five QTLs associated with PH at 7, 14, 21, and 28 DAS were located on chromosomes 1, 3, and 9 (Table 6 and Fig. 2) and explained $42.2 \%$ of PV. On chromosomes 1 and 9, two QTLs for PH at 14 DAS $\left(q P H-14_{1.1}\right.$, $\mathrm{PV}=8.7 \%$, and $q \mathrm{PH}-14_{9.1}, \mathrm{PV}=8.1 \%$ ) were marked 


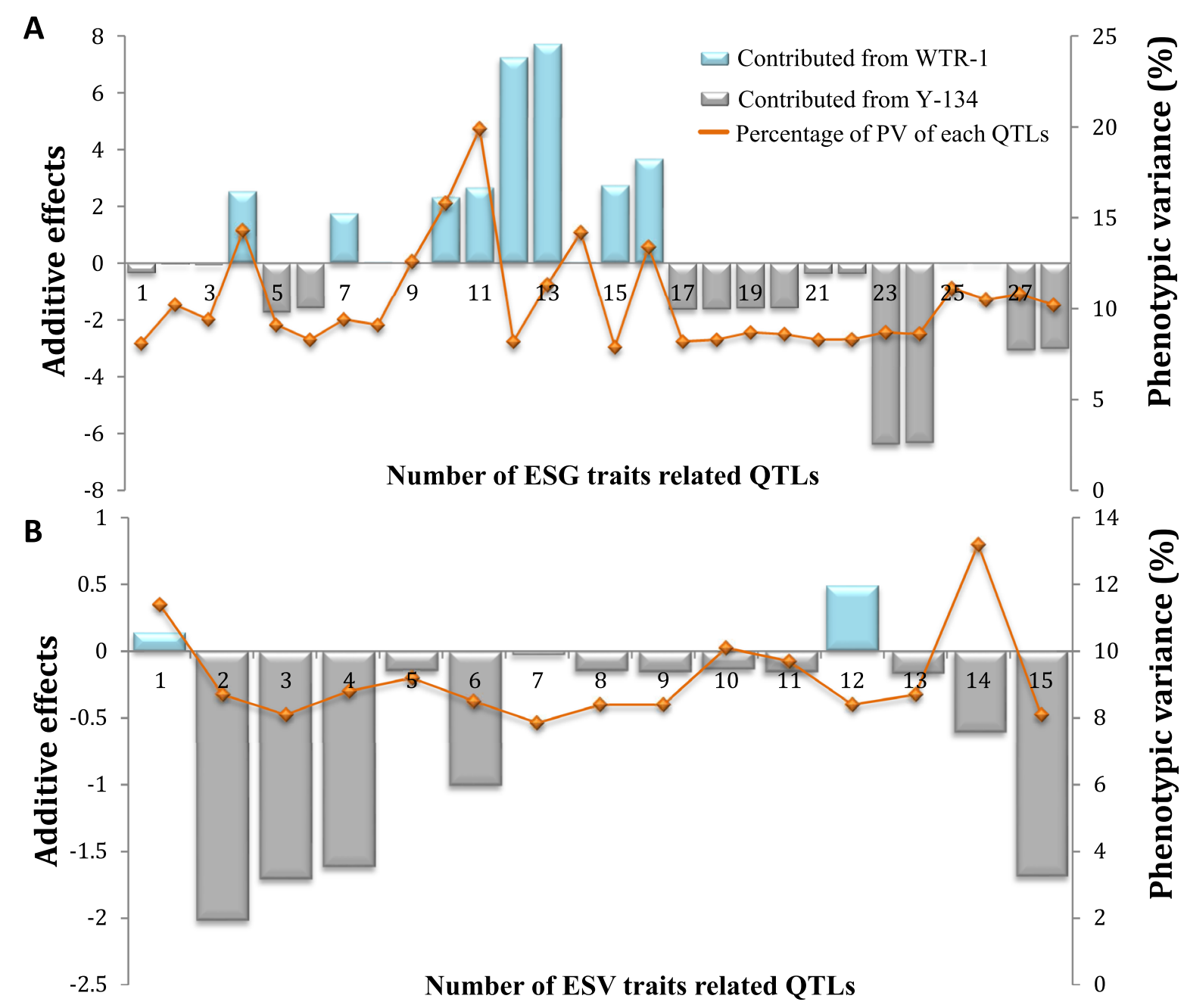

Fig. 3 QTLs strong effects of early seed germination (ESG) and early seedling vigor (ESV) traits (LOD > 3.0) identified in the early backcross generation of selective introgression lines

by SNP_1_42397588 and SNP_9_9834510. The other three remaining QTLs $\left(q P H-7_{3.1}, q P H-21_{1.1}\right.$, and $\left.q P H-28_{1.2}\right)$ were linked with $\mathrm{PH}$ at 7,21 , and 28 DAS, with LOD scores of $3.18(\mathrm{PV}=8.5 \%), 3.06$ $(\mathrm{PV}=8.1 \%)$, and $3.30(\mathrm{PV}=8.8 \%)$, respectively. The additive effect indicated that $\mathrm{Y}-134$ contributed to the desirable alleles (Fig. 3).

To date, there have been no reports on QTLs associated with NL at different growth stages. In this study, eight novel QTLs associated with NL were identified on chromosomes 1, 3, 6, 7, and 9 (Table 6). Among the eight novel QTLs, one major QTL ( $q N L$ $\left.7_{1.1}\right)$ and another minor QTL $\left(q N L-21_{7.1}\right)$ were contributed by the WTR-1 allele and the remaining six
(SILs). The plots A and B represent the additive effect and allele effect of the 29 QTLs in ESG and 15 QTLs in ESV QTLs

QTLs were influenced by a desirable allele coming from the donor parent Y-134 (Table 6 and Fig. 3). Among the novel QTLs, three were major QTLs and were associated with $\mathrm{NL}$ on chromosome $1\left(q N L-7_{1.1}\right.$, $\mathrm{PV}=11.4 \%)$, chromosome $6 \quad\left(q N L-7_{6.3}, \quad \mathrm{PV}=\right.$ $10.1 \%)$, and chromosome $9\left(q N L-7_{9.1}, \mathrm{PV}=13.2 \%\right)$, with LOD scores of 4.30, 3.78, and 5.04, respectively. The major QTL $\left(q N L-7_{1.1}\right)$ on chromosome 1 was marked by SNP_1_1022215 and exhibited the highest PV (11.4\%), with a LOD score of 4.3 (Table 6). 
Table 6 QTLs identified for early seedling vigor (ESV) traits related to weed competitive ability

\begin{tabular}{|c|c|c|c|c|c|c|c|c|c|}
\hline No. & QTL & Trait & Chr & Position (bp) & Peak marker & LOD & $\begin{array}{l}\text { Phenotypic } \\
\text { variance }(\%)\end{array}$ & Additive effect & Parent* \\
\hline 1 & $q N L-7_{1.1}$ & NL at 7 DAS & 1 & 1022215 & SNP_1_1022215 & 4.3 & 11.4 & 0.14 & WTR-1 \\
\hline 2 & $q P H-14_{1.1}$ & $\mathrm{PH}$ at $14 \mathrm{DAS}$ & 1 & 42397588 & SNP_1_42397588 & 3.2 & 8.7 & -2.02 & Y-134 \\
\hline 3 & $q P H-21_{1.1}$ & $\mathrm{PH}$ at $21 \mathrm{DAS}$ & 1 & 13777831 & SNP_1_13777831 & 3.0 & 8.1 & -1.71 & $\mathrm{Y}-134$ \\
\hline 4 & $q P H-28_{1.2}$ & $\mathrm{PH}$ at $28 \mathrm{DAS}$ & 1 & 24722142 & SNP_1_24722142 & 3.3 & 8.8 & -1.62 & Y-134 \\
\hline 5 & $q N L-7_{3.1}$ & NL at 7 DAS & 3 & 34568654 & SNP_3_34568654 & 3.4 & 9.2 & -0.15 & Y-134 \\
\hline 6 & $q P H-7_{3.1}$ & $\mathrm{PH}$ at 7 DAS & 3 & 2230854 & SNP_3_2230854 & 3.1 & 8.5 & -1.01 & Y-134 \\
\hline 7 & $q R D W_{3.1}$ & RDW & 3 & 34568654 & SNP_3_34568654 & 2.9 & 7.85 & -0.03 & Y-134 \\
\hline 8 & $q N L-7_{6.1}$ & NL at 7 DAS & 6 & 12183428 & SNP_6_12183428 & 3.1 & 8.4 & -0.15 & Y-134 \\
\hline 9 & $q N L-7_{6.2}$ & NL at 7 DAS & 6 & 17750942 & SNP_6_17750942 & 3.1 & 8.4 & -0.16 & Y-134 \\
\hline 10 & $q N L-7_{6.3}$ & $\mathrm{NL}$ at $7 \mathrm{DAS}$ & 6 & 25277863 & SNP_6_25277863 & 3.7 & 10.1 & -0.14 & $\mathrm{Y}-134$ \\
\hline 11 & $q R F W_{6.1}$ & RFW & 6 & 25277863 & SNP_6_25277863 & 3.6 & 9.7 & -0.16 & Y-134 \\
\hline 12 & $q N L-21_{7.1}$ & NL at $21 \mathrm{DAS}$ & 7 & 15241178 & SNP_7_15241178 & 3.1 & 8.4 & 0.49 & WTR-1 \\
\hline 14 & $q N L-21_{9.1}$ & NL at 21 DAS & 9 & 21885499 & SNP_9_21885499 & 3.2 & 8.7 & -0.61 & $\mathrm{Y}-134$ \\
\hline 13 & $q N L-7_{9.1}$ & NL at 7 DAS & 9 & 21896910 & SNP_9_21896910 & 5.0 & 13.2 & -0.17 & Y-134 \\
\hline 15 & $q P H-14_{9.1}$ & $\mathrm{PH}$ at $14 \mathrm{DAS}$ & 9 & 9834510 & SNP_9_9834510 & 3.0 & 8.1 & -1.69 & Y-134 \\
\hline
\end{tabular}

*Parent- contributing desirable allele. For the additive effect, a positive value means that the desirable allele is from the recipient parent (WTR-1), while a negative value means that the desirable allele is from the donor parent (Y-134). Abbreviations: Chr, chromosome; LOD, logarithm of the odds; DAS, days after sowing; NL at 7 DAS, number of leaves at 7 DAS; NL at 21 DAS, number of leaves at 21 DAS; PH at 7 DAS, plant height at 7 DAS; PH at 14 DAS, plant height at 14 DAS; PH at 21 DAS, plant height at 21 DAS; PH at 28 DAS, plant height at 28 DAS; RFW, root fresh weight; and RDW, root dry weight

Hotspots and co-localized QTLs for ESG and ESV traits

QTLs associated with WCA-related traits were identified in two hotspot regions on chromosomes 11 and 12. Eight QTLs were located on chromosome 11 at the position from 22.4 $\mathrm{Mb}$ to $27.9 \mathrm{Mb}$, and it was labeled as "QTL hotspot I", which covers a total genomic length of $5.5 \mathrm{Mb}$. Similarly, chromosome 12 contained a total of 12 QTLs that were located at the position from $14.8 \mathrm{Mb}$ to $25.7 \mathrm{Mb}$, and this was labeled as "QTL hotspot II", with a total coverage length of $10.9 \mathrm{Mb}$ (Fig. 2). QTL hotspot I was associated with five ESG-related traits (GP-1, 1st GC, VI-1, 2nd GC, and TDGS) grouped together with an average PV of $12.65 \%$, whereas QTL hotspot II contained five ESG-related traits (1st GC, 2nd GC, GP-1, VI-1, and TFGS) effectively showing the average PV of 9.19\%. Interestingly, chromosome 11 had an additive effect contributed by a WTR-1 allele. In contrast to chromosome 11, the additive allele from Y-134 contributed to all the QTLs on chromosome 12.
Taken together, $58.6 \%$ and $26.6 \%$ of the ESG and ESV QTLs were co-localized. ESV traits related to two QTLs ( $q N L-7_{6.3}$ and $\left.q R F W-7_{6.1}\right)$ on chromosome 6 were marked with SNP_6_25277863 at the position of $25.2 \mathrm{Mb}$ and two QTLs ( $q R D W_{3.1}$ and $q N L-7_{3.1}$ ) on chromosome 3 were marked by SNP_3_34568654 at the position of $34.5 \mathrm{Mb}$ and were co-localized. Both of these QTLs were contributed by a Y-134 allele. For ESG traits, three QTLs ( $q 1 \mathrm{st} G C_{11.2}, q T D G S_{11.1}$, and $\left.q V I-1_{11.2}\right)$ at $27.9 \mathrm{Mb}$, two QTLs $\left(q 2 \mathrm{nd} G C_{11.1}\right.$ and $\left.q G P-1_{11.2}\right)$ at $24.7 \mathrm{Mb}$, and two QTLs $\left(q 1 \mathrm{st} G C_{11.1}\right.$ and $\left.q V I-1_{11.1}\right)$ at $22.5 \mathrm{Mb}$ were co-localized on chromosome 11; whereas two QTLs (q1st $G C_{10.1}$ and $\left.q T D G S_{10.1}\right)$ at the position of $20.7 \mathrm{Mb}$ were colocalized on chromosome 10. These co-localized QTLs were contributed by a WTR-1 allele. Similarly, on chromosome 12, two QTLs ( $q 2$ nd $G C_{12.1}$ and $q G P$ $\left.1_{12.1}\right)$ at $16.2 \mathrm{Mb}$, two QTLs ( $q 2 \mathrm{nd} G C_{12.2}$ and $q G P$ $\left.1_{12.2}\right)$ at $17.9 \mathrm{Mb}$, and two other QTLs $\left(q T F G S_{12.2}\right.$ and $\left.q V I-1_{12.2}\right)$ at $25.7 \mathrm{Mb}$ were co-localized. The hotspot co-localized QTLs on chromosome 12 was associated with a desirable allele from Y-134. Interestingly, studies on the hotspot QTL regions revealed that the 
Table 7 Possible putative candidate genes identified from the hotspot QTL regions for weed competitive ability (WCA) traits in rice

\begin{tabular}{|c|c|c|c|c|c|c|}
\hline \multirow[t]{2}{*}{ No. } & \multirow[t]{2}{*}{ Chromosome } & \multicolumn{2}{|c|}{ CDS coordinates $\left(5^{\prime}-3^{\prime}\right)$} & \multirow[t]{2}{*}{ Name of the loci/gene } & \multirow[t]{2}{*}{ Locus } & \multirow{2}{*}{$\begin{array}{l}\text { Nucleotide } \\
\text { length (bp) }\end{array}$} \\
\hline & & Start & End & & & \\
\hline 1 & 11 & 22040368 & 22044971 & $\begin{array}{l}\text { Pentatricopeptide repeat domain containing } \\
\text { protein, putative, expressed }\end{array}$ & LOC_Os11g37330.1 & 2085 \\
\hline 2 & 11 & 22550213 & 22554890 & $\begin{array}{l}\text { Targeting protein for Xklp2, putative, } \\
\text { expressed }\end{array}$ & LOC_Os11g38010.1 & 1224 \\
\hline 3 & 11 & 24727308 & 24727862 & ATBPM6, putative & LOC_Os11g41240.1 & 555 \\
\hline 4 & 11 & 24780333 & 24781296 & Hypothetical protein & LOC_Os11g41320.1 & 240 \\
\hline 5 & 11 & 27997070 & 27991732 & $\begin{array}{l}\text { Tetratricopeptide repeat domain containing } \\
\text { protein, expressed }\end{array}$ & LOC_Os11g46230.1 & 2094 \\
\hline 6 & 12 & 14845431 & 14838519 & SAP domain containing protein, expressed & LOC_Os12g25640.1 & 537 \\
\hline 7 & 12 & 14933967 & 14933192 & Expressed protein & LOC_Os12g25760.1 & 354 \\
\hline 8 & 12 & 16278035 & 16279881 & Hypothetical protein & LOC_Os12g27650.1 & 495 \\
\hline 9 & 12 & 17441549 & 17443641 & ZmEBE-1 protein, putative, expressed & LOC_Os12g29370.1 & 909 \\
\hline 10 & 12 & 17786025 & 17788513 & $\begin{array}{l}\text { The protein of unknown function DUF502 } \\
\text { domain-containing protein, expressed }\end{array}$ & LOC_Os12g29750.1 & 825 \\
\hline 11 & 12 & 17900930 & 17903046 & Nodulin, putative, expressed & LOC_Os12g29950.1 & 1800 \\
\hline 12 & 12 & 19779505 & 19786587 & Flavin monooxygenase, putative, expressed & LOC_Os12g32750.1 & 1347 \\
\hline 13 & 12 & 25790709 & 25796385 & Expressed protein & LOC_Os12g41670.1 & 17,331 \\
\hline
\end{tabular}

alleles were associated with both parents, and this indicated that a wide range of the molecular and phenotypic diversity of ESG and ESV traits related to WCA existed among the SILs.

Putative candidate genes associated with ESG and ESV traits

The QTL hotspot regions and co-localized QTLs on chromosomes 11 and 12 were used to analyze the candidate genes for WCA in rice. A total of five possible genes on chromosome 11 and eight genes on chromosome 12 were identified (Table 7). Out of 13 putative genes, two were hypothetical, six were putative proteins, and the remaining five genes were well reported to be involved in multiple functions related to biotic and abiotic stress tolerance in rice. On chromosome 11, GP is associated with pentatricopeptide repeat (PPR) domain and three other co-localized QTLs $\left(q 1 \mathrm{st} G C_{11.2}, q T D G S_{11.1}\right.$, and $\left.q V I-1_{11.2}\right)$ were associated with tetra-tricopeptide repeat (TPR) domain at $22 \mathrm{Mb}$ and $27.9 \mathrm{Mb}$ positions, respectively. Earlier reports of Gothandam et al. (2005), Lin et al. (2015) and Yu et al. (2016) have suggested that PPR domain are located on different chromosomes. These domains are functionally related to chloroplast development, photosynthesis, seedling lethality during the early leaf growth stage, embryogenesis, seed development, and cytoplasmic male sterility (Sosso et al. 2012; Gong et al. 2014; Huang et al. 2015; Lin et al. 2015; Sharma and Pandey 2016). In addition to that, TPR-containing protein has been involved in several functions such as cell cycle, regulation of gibberellins (GAs), seed development, hybrid sterility, endosperm development, and seed setting (Awasthi et al. 2012; Lin et al. 2015). Similarly, other colocalized QTLs ( $q 1$ st $G C_{11.1}$ and $q V I-1_{11.1}$ ) at $22.5 \mathrm{Mb}$ on chromosome 11 are found within the range of $4 \mathrm{kbs}$ of Os11g38010. This locus has been reported to encode TPX2 homolog, which is considered to be involved in the organization of microtubule spindle formation during cell division (Guo et al. 2008). Two hypothetical and putative expressed loci $(\mathrm{Os} 1 \mathrm{~g} 41240$ and $O s 11 \mathrm{~g} 41320$ ) were found to be associated with the two QTLs ( $q 2$ nd $G C_{11.1}$ and $\left.q G P-1_{11.2}\right)$ mapped in this study.

On chromosome 12, QTL $q 1$ st $G C_{12.1}$ is associated with SAP domain-containing protein, which is functionally related to stress-associated proteins and are involved in regulating $\mathrm{GA}$ and $\mathrm{ABA}$ signaling in response to abiotic stresses (Huang et al. 2008; Giri et al. 2011; Zhang et al. 2015; Kothari et al. 2016). 
Growth hormone regulations are vital to seedling growth and development. The QTL $q T F G S_{12}$ is associated with $O s 12 \mathrm{~g} 32750$ at the position of 19.7 Mb. These loci are responsible for flavin monooxygenases, which have a significant functional role in the tryptophan (Trp)-dependent indole-acetic acid synthesis for auxin biosynthetic pathways for the improvement of quick response to early seedling growth and root tip development (Yamamoto et al. 2007; Fujino et al. 2008; Yi et al. 2013). Interestingly, we identified six loci (Os12g27650, Os12g29950 Os12g41670, Os12g25760, Os12g29370, and Os $12 \mathrm{~g} 29750$ ) that were associated with unknown and hypothetical proteins in the rice genome databases (Table 7).

\section{Discussion}

Breeding for WCA in rice is essential for the development of DSR varieties under both dry and wet-seeded methods. WCA provides rapid early growth toward crop establishment and suppression of weed growth in DSR and aerobic rice ecosystem. A significant positive correlation in traits such as germination percentage, germination count, and vigor index indicates a strong positive relationship with field emergence and seedling establishment, which are the favorable traits for WCA in rice. The Green Super Rice (GSR) breeding strategy (Zhang 2007; Ali et al. 2017, 2018; Dimaano et al. 2017) helped in developing the mapping population ideally selected for WCA traits in a systematic manner with progeny testing. Germination percentage of WTR-1 and Y-134 was $94 \%$ and $68 \%$, respectively; whereas the germination percentage of the SILs showed a significant variation from $2 \%$ to $98 \%$. The extreme phenotypic variation in germination indicates that transgressive segregation took place in the population. This also suggests that both parents possess positive QTLs and genes for WCA and that WCA is controlled by multiple QTLs and genes in rice. Based on the vigor index $(>120)$ and germination percentage $(>90)$ values, 17 SILs and 10 SILs were identified as promising SILs possessing ESV and ESG traits, respectively. Five SILs with ESG and 15 SILs with ESV were shown to maintain a higher germination percentage and vigor index than the parents. Two SILs were commonly identified as promising SILs in both experiments of
ESG and ESV. These promising SILs can be useful in breeding programs for the development of rice cultivars with WCA.

Mahender et al. (2015) reviewed and mentioned 38 QTLs that were associated with germination rate, germination index, and germination percentage and germination time in different genetic backgrounds of mapping populations. In the present study, the major QTL $q G P-1_{11.2}$ coincides with germination percentage, germination rate, and germination index on chromosome 11 and was also observed in the genetic background of recombinant inbred line (RIL) mapping populations of Daguandao (japonica) and IR28 (indica), respectively (Wang et al. 2010). Several QTLs for ESG-related traits (1st GC and 2nd GC) were previously reported: $q L T G-2$ on chromosome 2 (Miura et al. 2001), $q$ GR3-1 and $q G R 3-3$ on chromosome 3 (Cui et al. 2002a), qLTG-4-2, qLTG-4-1, and $q G P-4$ on chromosome 4 (Miura et al. 2001; Wang et al. 2010), $q$ GR5-1 and $q L T G-5$ on chromosome 5 (Miura et al. 2001; Cai and Morishima 2002; Cui et al. 2002a, b), qGR6-2 on chromosome 6 (Cui et al. 2002a; Wang et al. 2010), $q G R 7-1$ on chromosome 7 (Cui et al. 2002a), and $q L T G-11, q G R-11$, and $q G I-11$ on chromosome 11 (Saito et al. 2001; Wang et al. 2010) in the diverse sets of rice mapping populations such as RILs, BILs, and DHs. Some QTLs for ESG-related traits identified in this study co-localized with previously reported QTLs, e.g., $q 1$ st $G C_{5.1}$ co-localized with $q$ GR5-1 (Miura et al. 2001) on chromosome 5 (Fig. 2). On chromosome 11, $q 1$ st $G C_{11.1}, q G P-1_{11.2}$ and $q 2$ nd $G C_{11.1}$, and $q G P-1_{11.2}$ co-localized with qPH11.2 (Sandhu et al. 2014), qSV11c (Chen et al. 2019), and $q L T G-11$ (Saito et al. 2001), respectively. On chromosome $12, q l_{\text {st }} G C_{12.2}$ and $q V I-1_{12.1}$ colocalized with $q S V 12 b$ (Chen et al. 2019); while $q 2$ nd $G C_{12.2}$ and $q G P-1_{12.2}$ co-localized with $q A G 12$ (Septiningsih et al. 2013) (Fig. 2). Therefore, the colocalization of these QTLs will provide a genetic basis underlying the correlation among the traits. Chromosomes 11 and 12 contained more than five traits related to ESG, which indicates that they are actively associated with rapid seedling growth in rice. Out of 28 identified QTLs for ESG traits, eight GP and VI QTLs were reported earlier (Diwan 2006; Hayashi et al. 2008; Yang et al. 2010; Diwan et al. 2013; Anandan et al. 2016; Singh et al. 2017), while the remaining 20 QTLs were novel. 
Numerous morphological and physiological key traits are involved in ESV that determines the improvement of seedling growth and grain yield component traits (Mahender et al. 2015). Based on the comprehensive ESV QTL analysis, five chromosomes were harboring multiple trait-associated QTLs and co-localized promising QTLs for ESV in rice (Mahender et al. 2015). A total of 15 morphophysiological traits such as germination rate, shoot and root length, shoot fresh and dry weight, seedling early vigor, leaf area, reducing sugar content and field vigor were found on chromosome 1 (Yan et al. 1998; Marri et al. 2005; Lu et al. 2007; Zhou et al. 2007; Namuco et al. 2009; Wang et al. 2010; Cheng et al. 2013; Diwan et al. 2013; Dang et al. 2014). Seven traits like shoot length, shoot dry weight, germination rate, root length, seedling early vigor, seedling fresh weight, and coleorhiza length were found on chromosome 3 (Zhi-Hong et al. 2005; Lu et al. 2007; Zhou et al. 2007; Cheng et al. 2013). Similarly, chromosome 6 was associated with seven traits such as total dry weight, germination rate, shoot dry weight, reducing sugar content, seed size, germination percentage, and shoot length (Wang et al. 2010; Xie et al. 2014). Three traits such as germination rate, germination index and shoot length were found on chromosome 7 (Mei et al. 2005; Dang et al. 2014) and four traits like root activity, shoot dry weight, seed size and leaf area were found on chromosome 9 (Cui et al. 2002a) that were responsible for more than three ESV traits in different mapping populations.

Some QTLs for ESV-related traits identified in this study co-localized with previously reported QTLs such as $q$ SVIc (Chen et al. 2019) and $q$ GR-138 (Wang et al. 2010) co-localizing with $q P H-28_{1.2}$ on chromosome 1; qSV3a (Chen et al. 2019), $q G R 2$ (Diwan et al. 2013), qSEV-2-2 (Lu et al. 2007), and $q S D W 2$ (Han et al. 2007) co-localizing with $q P H-7_{3.1}$ on chromosome 3 ; and $q C D-9-3$ and $q C V-9$ (Yang et al. 2019) colocalizing with $q \mathrm{PH}-14_{9.1}$ on chromosome 9 (Fig. 2). Four QTLs contributing to NL at 7 DAS and PH at 14, 21 , and 28 DAS overlapped with earlier reported QTLs related to $15 \mathrm{ESV}$ traits on chromosome 1 at the physical position from $29.7 \mathrm{cM}$ (RM259) to $146.1 \mathrm{cM}$ (RM315). These ESV traits associated with QTLs were earlier reported by using a diverse genetic resource of rice accessions and biparental mapping populations (Yan et al. 1998; Marri et al. 2005; Cairns et al. 2009; Diwan et al. 2013; Dang et al. 2014). QTLs for $\mathrm{PH}$ at 14, 21 and $28 \mathrm{DAS}$ on chromosome 1 shared common genomic regions associated with SL, which was reported by Li et al. (2006), Namuco et al. (2009), Yan et al. (1998) and Zhou et al. (2007). Similarly, Diwan et al. (2013) identified six QTLs for SL in the 18.8 to $71.6 \mathrm{cM}$ region, which showed $10 \%$ to $15 \%$ significant PV. The identical chromosomal segment of the genomic region was controlling other ESV-related traits according to Redona and Mackill (1996) and Zhang et al. (2004). Interestingly, the $\alpha$-amylase gene amylB/A is located at $13 \mathrm{cM}$ (Temnykh et al. 2001), which is near the novel QTL $N L-7_{1.1}$ on chromosome 1. This gene may influence a higher germination rate and faster seedling growth at the early stage through the degradation of starch energy sources by $\alpha$-amylase in the rice embryo. The same genomic regions were controlling ESV traits and were frequently detected across other mapping populations of $O$. rufipogon and japonica cultivar 'Jefferson' (Thomson et al. 2003).

On chromosome 3, three ESV-related QTLs ( $q N L$ $7_{3.1}, q P H-7_{3.1}$, and $\left.q R D W_{3.1}\right)$ influence WCA in rice. The NL at 7 DAS and RDW QTLs overlapped in the same genomic region marked by SNP_3_34568654. In other reports, several ESV-related traits such as shoot length, shoot dry weight, germination rate, seedling early vigor, seedling fresh weight, and coleorhiza length were also mapped on chromosome 3 and were identified from two different RIL populations derived from Lemont/Teqing (Zhi-Hong et al. 2005; Lu et al. 2007; Zhou et al. 2007) and Jiucaiqing/IR26 (Cheng et al. 2013), a doubled-haploid population of CT9993/ IR62266 (Kanbar et al. 2006), $\mathrm{BC}_{3} \mathrm{~F}_{4}$ lines from Swarna/Moroberekan (Singh et al. 2017), and a natural diverse germplasm of rice accessions (Dang et al. 2014). Further, in support to the findings on chromosome 3, Singh et al. (2017) recently reported a QTL hotspot in the chromosome 3 region that had three possible candidate genes (Os03g0236200, Os03g0324300, and Os03g0428700). These genes are involved in different roles for the development of young seedling, mesocotyl length, coleoptile elongation, and increasing physiological activity via changes in the ethylene signaling mechanism in cell differentiation, elongation, enzyme activities, and expansion genes, which demonstrate early seedling emergence and growth development.

On chromosome 6, four QTLs $\left(q N L-7_{6.1}, q N L-7_{6.2}\right.$, $q N L-7_{6.3}$, and $q R F W_{6.1}$ ) were mapped, while two QTLs $\left(q N L-7_{6.3}\right.$ and $\left.q R F W_{6.1}\right)$ overlapped with the 
same genetic marker of SNP_6_25277863. In other reports, the QTLs located in the region of 48.7 to $101.1 \mathrm{cM}$ of chromosome 6 were associated with six ESV-related traits such as germination rate, shoot dry weight, reducing sugar content, seed size, germination percentage, and shoot length in two different recombinant populations from ZS97/MH63 (Xie et al. 2014) and Daguandao/IR28 (Wang et al. 2010). The same genetic region is very close to the other QTLs: $q G W-6$ for the 1000-seed weight (Wan et al. 2005), sd6.1 for seed dormancy ( $\mathrm{Li}$ et al. 2006), $q E V_{6.1}$ for early vigor, $q E U E_{6.1}$ for early uniform emergence, and $q S H L_{6.1}$ for shoot length at 21 DAS (Singh et al. 2017).

On chromosome 7, the QTL controlling NL at 21 DAS ( $\left.q N L-21_{7.1}\right)$ was associated with previous reports on six ESV-related traits such as shoot length and tiller number, weight of mobilized seed reserve, leaf area, germination rate, and germination index in the QTL mapping studies from RILs (Mei et al. 2005; Zhi-Hong et al. 2005; Wang et al. 2010; Cheng et al. 2013), $\mathrm{BC}_{3} \mathrm{~F}_{3}$ (Namuco et al. 2009), and natural germplasms (Dang et al. 2014). Three QTLs controlling NL at 7 and 21 DAS and PH at 14 DAS ( $q N L-7_{9.1}, q P H-14_{9.1}$, and $q N L-21_{9.1}$ ) were mapped on chromosome 9 . The physical position of the novel QTL located on chromosome 9 at 87.5 and $39.3 \mathrm{cM}$ was close to the genomic region and was associated with three ESV traits such as shoot dry weight, root activity, and seed weight in the genetic background of RILs (Zhenshan 97 and Minghui 63) reported by Cui et al. (2002a). The co-localization of all the QTLs related to ESV morphological traits such as germination-attributed traits, shoot and root length, fresh and dry weight of shoot and root, and mesocotyl length, and physiological traits such as reducing sugar, photosynthetic performance, leaf area, chlorophyll content, amylase activity, nitrate reductase, peroxidase, growth regulation hormones (abscisic acid, auxin, and gibberellins), and antioxidant enzymes (glutamic acid decarboxylase activity) located in the same genetic region provided valuable genomic information for improving WCA in rice.

To date, there is no published evidence on QTLs for rice WCA traits such as periodic germination counts, germinated seedlings with fresh and dry weight, number of leaves at 7 and 21 DAS, and average fresh weight of seedlings. Here, we identified novel QTLs for these traits. The novel and co-localized QTLs on chromosomes 3, 11, and 12 were associated with multiple traits, such as 1st GC, 2nd GC, VI-1, GP-1, TDGS, and TFGS. These QTLs were strongly correlated with ESG and ESV traits. Therefore, further high-resolution mapping studies are required for the validation of the expression and pleiotropic effect of these QTLs. However, the majority of early QTL studies have reported that multiple ESV traits are controlled by the same genomic region of reported chromosomes 1, 3, 5, 6, 9, 11, and 12 (Miura et al. 2001; Cai and Morishima 2002; Cui et al. 2002a, b; Kanbar et al. 2006; Koseki et al. 2010; Cheng et al. 2013; Diwan et al. 2013; Dang et al. 2014; Mahender et al. 2015; Singh et al. 2017). The novel QTLs accounting for a higher LOD and PV could be a potential target in future breeding programs and subsequent studies are needed to find the candidate genes and alleles for the strong association to understand the physiological and molecular mechanism conferring WCA.

\section{Conclusions}

WCA is a vital target trait that needs to be considered by rice breeders in developing DSR varieties. A systematic GSR breeding strategy involving early backcross breeding with phenotypic selection and progeny testing for WCA traits led to the development of a population for genetic analysis. This approach led to the identification of donors for QTLs, and genes for many of the WCA traits essential to the development of rice varieties for DSR and aerobic systems. The identification of QTLs for ESG and ESV is critical for accelerating breeding programs for weed competitive rice cultivars. Therefore, the present study attempted to identify the chromosomal regions and the QTLs governing these traits. The overall WCA QTLs were contributed by both parents, WTR-1 and Y-134. Out of 43 QTLs, 30 were contributed by a desirable allele from Y-134, whereas 13 were contributed by a desirable allele from WTR-1. The frequency of ESG and ESV traits associated with QTLs showed continuous segregation, and it is controlled by multiple QTLs and genes in rice. As many as 28 novel QTLs were identified from a total of 43 QTLs that govern the genetic mechanism of WCA. Among these, the majority of the QTLs were associated with two hotspot QTL regions: on chromosome 11 with eight QTLs detected and on chromosome 12 with 12 QTLs 
detected, and a few of them were co-localized QTLs. The hotspot and co-localized QTL regions could have a higher potential role in the improvement of WCA. In silico analysis of the QTL hotspots on chromosomes, 11 and 12 regarding their respective genomic positions revealed that two hypothetical and six putative candidate genes were located in these hotspots. Further investigation to fine-map and use of cloning strategies are required to identify novel candidate genes for WCA in rice. The two promising SILs that were identified to have both the ESG and ESV traits could be directly used in DSR breeding programs. The prominent QTLs from the promising SILs for WCA traits can be used in the development of functional markers and QTL pyramiding with desirable genetic backgrounds. These markers could be further employed for the introgression of genes/QTLs into elite rice cultivars through a marker-assisted selection in the plant breeding program for rice varieties with WCA.

Acknowledgments The authors would like to thank those who participated in the internal review of the manuscript at the International Rice Research Institute for improving it through valuable suggestions and much effort.

Author contribution ND conducted the phenotypic experiment. $\mathrm{PC}, \mathrm{AB}, \mathrm{MD}, \mathrm{YP}$, and $\mathrm{ND}$ recorded the observations of phenotypic traits and generated genotypic information. ND, BA, YP, and AM performed the statistical analysis, and ND and AM performed interpretation, drafting, and revision of the manuscript. JA and ZL were involved in designing the entire screen house experiment and in the critical revision of the manuscript. Finally, JA conceived the study and contributed to the critical revision of the final manuscript. All authors approved the final version of the manuscript.

Funding The authors would like to thank and acknowledge the Bill \& Melinda Gates Foundation (BMGF) for providing the research grant to ZL for the Green Super Rice Project under ID OPP1130530. We would also like to thank the Department of Agriculture (DA), Philippines, for providing funds to JA under the Next-Gen project.

\section{Compliance with ethical standards}

Conflict of interest The authors declare that they have no conflict of interest.

Ethical standards We declare that the present experiments comply with the ethical standards of the International Rice Research Institute (IRRI), Philippines.

Open Access This article is licensed under a Creative Commons Attribution 4.0 International License, which permits use, sharing, adaptation, distribution and reproduction in any medium or format, as long as you give appropriate credit to the original author(s) and the source, provide a link to the Creative Commons licence, and indicate if changes were made. The images or other third party material in this article are included in the article's Creative Commons licence, unless indicated otherwise in a credit line to the material. If material is not included in the article's Creative Commons licence and your intended use is not permitted by statutory regulation or exceeds the permitted use, you will need to obtain permission directly from the copyright holder. To view a copy of this licence, visit http://creativecommons.org/licenses/by/4.0/.

\section{References}

Ali J, Xu J-LL, Gao Y-MM et al (2017) Harnessing the hidden genetic diversity for improving multiple abiotic stress tolerance in rice (Oryza sativa L.). PLoS ONE 12:e172515. https://doi.org/10.1371/journal.pone. 0172515

Ali J, Aslam UM, Tariq R et al (2018) Exploiting the genomic diversity of rice (Oryza sativa L.): SNP-typing in 11 earlybackcross introgression-breeding populations. Front Plant Sci 9:849. https://doi.org/10.3389/fpls.2018.00849

Anandan A, Anumalla M, Pradhan SK, Ali J (2016) Population structure, diversity and trait association analysis in rice (Oryza sativa L.) germplasm for early seedling vigor (ESV) using trait linked SSR markers. PLoS ONE 11:0152406

Anwar MP, Juraimi AS, Puteh A et al (2012) Seed priming influences weed competitiveness and productivity of aerobic rice. Acta Agric Scand Sect B-Soil Plant Sci 62:499-509

Appleby AP, Müller F, Carpy S (2002) Weed control. Ullmann's Encyclopedia of Industrial Chemistry. Weinheim: Wiley-VCH; 2002. https://doi.org/10.1002/14356007. a28_165

Awasthi A, Paul P, Kumar S et al (2012) Abnormal endosperm development causes female sterility in rice insertional mutant OsAPC6. Plant Sci 183:167-174

Cai H, Morishima H (2002) QTL clusters reflect character associations in wild and cultivated rice. Theor Appl Genet 104:1217-1228

Cairns JE, Namuco OS, Torres R et al (2009) Investigating early vigour in upland rice (Oryza sativa L.): Part II. Identification of QTLs controlling early vigour under greenhouse and field conditions. Field Crops Res 113:207-217

Caton BP, Cope AE, Mortimer M (2003) Growth traits of diverse rice cultivars under severe competition: implications for screening for competitiveness. Field Crops Res 83:157-172

Chauhan BS, Abugho SB (2013) Weed management in mechanized-sown, zero-till dry-seeded rice. Weed Technol 27:28-33

Chauhan BS, Awan TH, Abugho SB, Evengelista G (2015) Effect of crop establishment methods and weed control 
treatments on weed management, and rice yield. Field Crops Res 172:72-84

Chen K, Zhang Q, Wang CC et al (2019) Genetic dissection of seedling vigour in a diverse panel from the 3000 Rice (Oryza sativa L.) genome project. Sci Rep 9:1-15

Cheng X, Cheng J, Huang X et al (2013) Dynamic quantitative trait loci analysis of seed reserve utilization during three germination stages in rice. PLoS ONE 8:e80002

Churchill GA, Doerge RW (1994) Empirical threshold values for quantitative trait mapping. Genetics 138:963-971

Cui K, Peng S, Xing Y et al (2002a) Molecular dissection of seedling-vigor and associated physiological traits in rice. Theor Appl Genet 105:745-753

Cui K, Peng S, Xing Y et al (2002b) Molecular dissection of relationship between seedling characteristics and seed size in rice. Acta Bot Sin 44:702-707

Dang X, Thi TGT, Dong G et al (2014) Genetic diversity and association mapping of seed vigor in rice (Oryza sativa L.). Planta 239:1309-1319

Development Core Team R (2012) A language and environment for statistical computing. R Foundation for Statistical Computing, Vienna

Dimaano NGB, Ali J, Cruz PCSS et al (2017) Performance of newly developed weed-competitive rice cultivars under lowland and upland weedy conditions. Weed Sci 65:798-817. https://doi.org/10.1017/wsc.2017.57

Diwan JR (2006) DNA marker assisted genetic analysis of early vigor related traits in rice (Oryza sativa L.). Doctoral Dissertation, UAS Dharwad

Diwan J, Channbyregowda M, Shenoy V et al (2013) Molecular mapping of early vigour related QTLs in rice. Res J Biol $1: 24-30$

Fujino K, Matsuda Y, Ozawa K et al (2008) NARROW LEAF 7 controls leaf shape mediated by auxin in rice. Mol Genet Genom 279:499-507

Giri J, Vij S, Dansana PK, Tyagi AK (2011) Rice A20/AN1 zinc-finger containing stress-associated proteins (SAP1/ 11) and a receptor-like cytoplasmic kinase (OsRLCK253) interact via A20 zinc-finger and confer abiotic stress tolerance in transgenic Arabidopsis plants. New Phytol 191:721-732

Gong X, Su Q, Lin D et al (2014) The rice OsV4 encoding a novel pentatricopeptide repeat protein is required for chloroplast development during the early leaf stage under cold stress. J Integr Plant Biol 56:400-410

Gothandam KM, Kim E-S, Cho H, Chung Y-Y (2005) OsPPR1, a pentatricopeptide repeat protein of rice is essential for the chloroplast biogenesis. Plant Mol Biol 58:421-433

Guo L, Ho C-MK, Kong Z et al (2008) Evaluating the microtubule cytoskeleton and its interacting proteins in monocots by mining the rice genome. Ann Bot 103:387-402

Han L, Qiao Y, Zhang S et al (2007) Identification of quantitative trait loci for cold response of seedling vigor traits in rice. J Genet Genom 34:239-246

Haque AH, Akon MA, Islam MA, Khalequzzaman KM, Ali MA (2007) Study of seed health, germination and seedling vigor of farmers produced rice seeds. Int J Sustain Crop Prod 2(5):34-39

Hayashi E, Aoyama N, Still DW (2008) Quantitative trait loci associated with lettuce seed germination under different temperature and light environments. Genome 51:928-947
Huang J, Wang M-M, Jiang Y et al (2008) Expression analysis of rice A20/AN1-type zinc finger genes and characterization of ZFP177 that contributes to temperature stress tolerance. Gene 420:135-144

Huang X, Yang S, Gong J et al (2015) Genomic analysis of hybrid rice varieties reveals numerous superior alleles that contribute to heterosis. Nat Commun 6:6258

[IRRI] International Rice Research Institute (2017) Plant Breeding Tools. Manila, Philippines: IRRI. http://irri.org/ products

Jennings PR, de Jesus J (1964) Effect of heat on breaking seed dormancy in rice 1. Crop Sci 4:530-533

Kanbar A, Janamatti M et al (2006) Mapping QTLs underlying seedling vigour traits in rice (Oryza sativa L.). Curr Sci 90:24-26

Kaur S, Singh S (2014) Influence of crop density on weeds, growth and yield of direct-seeded rice. Indian J Weed Sci 46:318-321

Khan FA, Narayan S, Bhat SA, Maqbool R (2016) Vermipriming-a noble technology for seed invigouration in rice (Oryza sativa L.). SKUAST J Res 18:124-129

Koseki M, Kitazawa N, Yonebayashi S et al (2010) Identification and fine mapping of a major quantitative trait locus originating from wild rice, controlling cold tolerance at the seedling stage. Mol Genet Genom 284:45-54

Kothari KS, Dansana PK, Giri J, Tyagi AK (2016) Rice stress associated protein 1 (OsSAP1) interacts with aminotransferase (OsAMTR1) and pathogenesis-related 1a protein (OsSCP) and regulates abiotic stress responses. Front Plant Sci 7:1057

Lee H-S, Sasaki K, Higashitani A, et al (2012) Mapping and characterization of quantitative trait loci for mesocotyl elongation in rice (Oryza sativa L.). Rice 5:13

Li C, Zhou A, Sang T (2006) Genetic analysis of rice domestication syndrome with the wild annual species, Oryza nivara. New Phytol 170:185-194

Lin D, Gong X, Jiang Q et al (2015) The rice ALS3 encoding a novel pentatricopeptide repeat protein is required for chloroplast development and seedling growth. Rice 8:17

Lu XL, Niu AL, Cai HY et al (2007) Genetic dissection of seedling and early vigor in a recombinant inbred line population of rice. Plant Sci 172:212-220

Mahajan G, Ramesha MS, Chauhan BS (2014) Response of rice genotypes to weed competition in dry direct-seeded rice in India. Sci World J Article ID 641589. doi:10.1155/2014/ 641589

Mahender A, Anandan A, Pradhan SK (2015) Early seedling vigour, an imperative trait for direct-seeded rice: an overview on physio-morphological parameters and molecular markers. Planta 241:1027-1050

Marri PR, Sarla N, Reddy LV, Siddiq EA (2005) Identification and mapping of yield and yield related QTLs from an Indian accession of Oryza rufipogon. BMC Genet 6:33

Matsushima KI, Sakagami JI (2013) Effects of seed hydropriming on germination and seedling vigor during emergence of rice under different soil moisture conditions. Am J Plant Sci 4:1584. https://doi.org/10.4236/ajps.2013. 48191

Mei HW, Li ZK, Shu QY et al (2005) Gene actions of QTLs affecting several agronomic traits resolved in a 
recombinant inbred rice population and two backcross populations. Theor Appl Genet 110:649-659

Meng L, Li H, Zhang L, Wang J (2015) QTL IciMapping: integrated software for genetic linkage map construction and quantitative trait locus mapping in biparental populations. Crop J 3:269-283

Miura K, Lin SY, Yano M, Nagamine T (2001) Mapping quantitative trait loci controlling low temperature germinability in rice (Oryza sativa L.). Breed Sci 51:293-299

Murray MG, Thompson WF (1980) Rapid isolation of high molecular weight plant DNA. Nucleic Acids Res 8:4321-4326

Najeeb S, Ali J, Mahender A et al (2020) Identification of maineffect quantitative trait loci (QTLs) for low-temperature stress tolerance germination-and early seedling vigor-related traits in rice (Oryza sativa L.). Mol Breed 40:10

Namuco OS, Cairns JE, Johnson DE (2009) Investigating early vigour in upland rice (Oryza sativa L.): Part I. Seedling growth and grain yield in competition with weeds. Field Crops Res 113:197-206

Ni H, Moody K, Robles RP et al (2000) Oryza sativa plant traits conferring competitive ability against weeds. Weed Sci 48:200-204

Okami M, Kato Y, Yamagishi J (2011) Role of early vigor in adaptation of rice to water-saving aerobic culture: effects of nitrogen utilization and leaf growth. Field Crops Res 124:124-131

Pandey P, Irulappan V, Bagavathiannan MV, Senthil-Kumar M (2017) Impact of combined abiotic and biotic stresses on plant growth and avenues for crop improvement by exploiting physio-morphological traits. Front Plant Sci 8:537

Pang Y, Chen K, Wang X et al (2017) Simultaneous improvement and genetic dissection of salt tolerance of rice (Oryza sativa L.) by designed QTL pyramiding. Front Plant Sci 8:1275. https://doi.org/10.3389/fpls.2017.01275

Rahman M, Juraimi AS, Suria J et al (2012) Response of weed flora to different herbicides in aerobic rice system. Sci Res Essays 7:12-23

Rao AN, Johnson DE, Sivaprasad B et al (2007) Weed management in direct-seeded rice. Adv Agron 93:153-255

Ray DK, Mueller ND, West PC, Foley JA (2013) Yield trends are insufficient to double global crop production by 2050 . PLoS ONE 8:e66428

Redona ED, Mackill DJ (1996) Mapping quantitative trait loci for seedling vigor in rice using RFLPs. Theor Appl Genet 92:395-402

Saito K, Miura K, Nagano K et al (2001) Identification of two closely linked quantitative trait loci for cold tolerance on chromosome 4 of rice and their association with anther length. Theor Appl Genet 103:862-868

Sandhu N, Torres RO, Sta Cruz MT et al (2014) Traits and QTLs for development of dry direct-seeded rainfed rice varieties. J Exp Bot 66:225-244. https://doi.org/10.1093/jxb/eru413

Septiningsih EM, Ignacio JCI, Sendon P et al (2013) QTL mapping and confirmation for tolerance of anaerobic conditions during germination derived from the rice landrace Ma-Zhan Red. Theor Appl Gen. 126:1357-1366. https:// doi.org/10.1007/s00122-013-2057-1
Sharma M, Pandey GK (2016) Expansion and function of repeat domain proteins during stress and development in plants. Front Plant Sci 6:1218

Singh K, Kumar V, Saharawat YS et al (2013) Weedy rice: an emerging threat for direct-seeded rice production systems in India. J Rice Res 1:106

Singh H, Jassal RK, Kang JS et al (2015) Seed priming techniques in field crops-A review. Agric Rev 36:251-264

Singh UM, Yadav S, Dixit S, Ramayya PJ (2017) QTL hotspots for early vigor and related traits under dry direct-seeded system in rice (Oryza sativa L.). Front Plant Sci 8:1-14. https://doi.org/10.3389/fpls.2017.00286

Sosso D, Mbelo S, Vernoud V et al (2012) PPR2263, a DYWsubgroup pentatricopeptide repeat protein, is required for mitochondrial nad5 and cob transcript editing, mitochondrion biogenesis, and maize growth. Plant Cell 24(2):676-691. https://doi.org/10.1105/tpc.111.091074

Temnykh S, DeClerck G, Lukashova A et al (2001) Computational and experimental analysis of microsatellites in rice (Oryza sativa L.): frequency, length variation, transposon associations, and genetic marker potential. Genome Res 11:1441-1452. https://doi.org/10.1101/gr.184001

Thomson MJ, Tai TH, McClung AM et al (2003) Mapping quantitative trait loci for yield, yield components and morphological traits in an advanced backcross population between Oryza rufipogon and the Oryza sativa cultivar Jefferson. Theor Appl Genet 107:479-493

Wan XY, Wan JM, Weng JF, Jiang L, Bi JC, Wang CM, Zhai HQ (2005) Stability of QTLs for rice grain dimension and endosperm chalkiness characteristics across eight environments. Theor Appl Genet 110(7):1334-1346

Wang Z, Wang J, Bao Y et al (2010) Quantitative trait loci analysis for rice seed vigor during the germination stage. J Zhejiang Univ Sci B 11:958-964

Wolfe D, Dudek S, Ritchie MD, Pendergrass SA (2013) Visualizing genomic information across chromosomes with PhenoGram. BioData Min 6:18

Xie L, Tan Z, Zhou Y et al (2014) Identification and fine mapping of quantitative trait loci for seed vigor in germination and seedling establishment in rice. J Integr Plant Biol 56:749-759

Yamamoto Y, Kamiya N, Morinaka Y et al (2007) Auxin biosynthesis by the YUCCA genes in rice. Plant Physiol 143:1362-1371

Yan J, Zhu J, He C et al (1998) Molecular dissection of developmental behavior of plant height in rice (Oryza sativa L.). Genetics 150:1257-1265

Yang W, Yuan GUO, De-Lin H (2010) Discovery of elite alleles for seed vigor traits in two populations of japonica rice in Taihu lake region. Acta Agron Sin 36:754-763

Yang J, Sun K, Li D et al (2019) Identification of stable QTLs and candidate genes involved in anaerobic germination tolerance in rice via high-density genetic mapping and RNA-Seq. BMC Genom 20:355

Yi J, Liu L, Cao Y et al (2013) Cloning, characterization and expression of $\mathrm{SFMO}_{(t)}$ in rice encoding a flavinmonooxygenase. J Genet 92:471-480

Yu Y, Zhao Z, Shi Y et al (2016) Hybrid sterility in rice (Oryza sativa L.) involves the tetratricopeptide repeat domain containing protein. Genetics 203(3):1439-1451 
Zhang Q (2007) Strategies for developing Green Super Rice. Proc Natl Acad Sci 104:16402-16409. https://doi.org/10. 1073/pnas.0708013104

Zhang X, Fowler SG, Cheng H et al (2004) Freezing-sensitive tomato has a functional $\mathrm{CBF}$ cold response pathway, but a $\mathrm{CBF}$ regulon that differs from that of freezing-tolerant Arabidopsis. Plant J 39:905-919

Zhang Y, Lan H, Shao Q et al (2015) An A20/AN1-type zinc finger protein modulates gibberellins and abscisic acid contents and increases sensitivity to abiotic stress in rice (Oryza sativa). J Exp Bot 67:315-326

Zhang A, Liu C, Chen G et al (2017) Genetic analysis for rice seedling vigor and fine mapping of a major QTL qSSL1b for seedling shoot length. Breed Sci 67:307-315. https:// doi.org/10.1270/jsbbs. 16195

Zhao DL, Atlin GN, Bastiaans L, Spiertz JHJ (2006a) Cultivar weed-competitiveness in aerobic rice: heritability, correlated traits, and the potential for indirect selection in weed-free environments. Crop Sci 46:372-380

Zhao DL, Atlin GN, Bastiaans L, Spiertz JHJ (2006b) Developing selection protocols for weed competitiveness in aerobic rice. Field Crops Res 97:272-285

Zhi-Hong Z, Li S, Wei L et al (2005) A major QTL conferring cold tolerance at the early seedling stage using recombinant inbred lines of rice (Oryza sativa L.). Plant Sci 168:527-534

Zhou L, Wang JK, Yi Q et al (2007) Quantitative trait loci for seedling vigor in rice under field conditions. Field Crops Res 100:294-301

Publisher's Note Springer Nature remains neutral with regard to jurisdictional claims in published maps and institutional affiliations. 